\title{
Are there Monday effects in Stock Returns: A Stochastic Dominance Approach*
}

\author{
Young-Hyun $\mathrm{Cho}^{\dagger}$ \\ Korea University
}

\author{
Oliver Linton \\ London School of Economics
}

September 29, 2006

\author{
Yoon-Jae Whang§ \\ Seoul National University
}

\begin{abstract}
We provide a test of the Monday effect in daily stock index returns. Unlike previous studies we define the Monday effect based on the stochastic dominance criterion. This is a stronger criterion than those based on comparing means used in previous work and has a well defined economic meaning. We apply our test to a number of stock indexes including large caps and small caps as well as UK and Japanese indexes. We find strong evidence of a Monday effect in many cases under this stronger criterion. The effect has reversed or weakened in the Dow Jones and S\&P 500 indexes post 1987, but is still strong in more broadly based indexes like the NASDAQ, the Russell 2000 and the CRSP.
\end{abstract}

KEYWORDS: Efficient Markets; stock market anomalies; subsampling

JEL Classification: C12,C14,C15,G13,G14

${ }^{*}$ Thanks to Franz Palm, Andrew Patton, and a referee for comments. Thanks especially to Anisha Ghosh for research assistance and many comments. GAUSS computer code is available from the authors for carrying out all the routines of this paper.

${ }^{\dagger}$ Department of Business Administration, Korea University, Seoul 136-701, Korea. Email Address : chometrics@korea.ac.kr

‡Department of Economics, London School of Economics, Houghton Street, London WC2A 2AE, United Kingdom. E-mail address: o.linton@lse.ac.uk. This research was supported in part through a grant from the Economic and Social Science Research Council.

$\S$ Department of Economics, Seoul National University, Seoul 151-742, Korea. Email Address: whang@snu.ac.kr. This work was supported by the Korea Research Foundation Grant funded by the Korean Government (MOEHRD) (KRF-2005-041-B00074). 


\section{Introduction}

The efficient market hypothesis (EMH) suggests that at any given time prices fully reflect all available information on a particular stock market. Thus, according to the (weak form) EMH, no investor can gain an advantage in predicting the return on a stock using publicly available information. However, there is a lot of evidence against the EMH in the real world of investment. There is an extensive literature on anomalies in financial markets including size effects, stock split effects, and monthly seasonals, see for example the recent volume of Keim and Ziemba (2000) for a general discussion. It is well documented that some predictable patterns exist in the day-of-the-week returns. The phenomenon that the Monday (close Friday to close Monday) stock returns, on average, are less than returns on any other day of the week and indeed nett returns are negative has been called the Monday effect (or weekend effect) in the literature. There are other definitions of the 'Monday effect', and we will examine a number of different hypotheses capturing the general spirit of this phenomenon.

The Monday effect in the US stock market is extensively documented during the 1980's, see e.g., French (1980), Gibbons and Hess (1981), Rogalski (1984), and Keim and Stambaugh (1984). On the other hand, some recent papers present evidence that the Monday effect in the US and UK stock markets has gradually disappeared. For example, Fortune (1998) shows that after 1987 there is no evidence of a negative weekend return. Mehdian and Perry (2001) show that in the 1987-1998 period Monday returns are not significantly different from returns during the rest of the week for the SP500, DJCOMP and NYSE (large-cap) indexes. Coutts and Hayes (1999) also show empirically that the Monday effect exists but is not as strong as has been previously documented for the UK stock indexes, see also Steeley (2001). Wang, Li, and Erickson (1997) show that the Monday effect (negative returns) occurs primarily in the last two weeks of the month for a number of stock indexes consistently over the period 1962-1993, while returns for the first part of the month are not statistically significantly different from zero.

What are the explanations for differences in expected returns across days of the week? There are four types of explanation. First, that this is a statistical artifact obtained by data-snooping. Recently, Sullivan, Timmerman, and White (2001) made this critique of the calendar effects literature. They applied a statistical procedure that controls for data-mining in testing for calendar effects. They found that the Monday effect was much less statistically significant than in previous studies. Their results were obtained on the DJIA over the period 1896-1996. Hansen, Lunde, and Nason (2005) have extended this work. Both these papers compare expected returns or Sharpe ratios. The second class of explanations involve market microstructure, specifically, issues about settlement, dividends, and taxes. For example, French (1980) proposed the calendar time hypothesis, which would suggest that 
expected returns be actually larger over the weekend (Friday to Monday) because of the three calendar days in-between versus the usual one calendar day for other days of the week. This hypothesis is at odds with the data. Lakonishok and Levi (1982) suggest that expected returns should be different across days due to the 5-day settlement period, which has the effect of making expected returns higher on Fridays and lower on Mondays relative to either a trading or calendar time model. The general consensus appears to be that the data does not support the precise predictions of their hypothesis, see Pettengill (2003). The third class of explanations involve different rates of flow of micro and macro information. Basically, the release of bad news tends to be delayed until the weekend, French (1980). Steeley (2001) argues that the Monday effect in the UK stock market is related to the systematic pattern of market wide news arrivals that concentrates between Tuesdays and Thursdays. However, a number of studies have found that this does not explain the whole effect, see Pettengill (2003). The fourth class of explanations invokes the differential trading patterns of various market participants. Individuals are net sellers on Mondays, and individuals behave differently on Mondays versus other days of the week. Or else, it could also be due to short selling activity -short sellers close their position on Fridays as it is difficult to monitor over weekends (perhaps most of them go on holiday). They sell the stocks on Monday leading to a fall in prices. There are some studies that have documented different behaviour of individuals on Mondays versus other days. For example, Pettengill (1993) finds that individuals were much more likely to invest in risky assets when the experiments were conducted on Fridays than when they were on Mondays. ${ }^{1}$ There are a wide range of views on the significance of this effect in explaining stock market anomalies. Finally, others have questioned the magnitude of the Monday effect and whether it is sufficiently large to generate profits based on simple trading rules, French (1980).

The purpose of this paper is to investigate empirically the existence of the Monday effect in major stock markets using the stochastic dominance (hereafter SD) criterion. The above approaches have all been based on a comparison of expected returns or Sharpe ratios. The validity of these approaches can be questioned on many grounds. Comparison of expected returns is questionable because there may always be omitted risk factors that account for the differences in mean returns. Mean variance analysis can be formally justified on economic grounds only under either normal returns or quadratic utility. Both of these hypotheses are questionable on logical and empirical

\footnotetext{
${ }^{1}$ Interestingly, there appear to be 'weekend' effects in a wide range of other social and physical phenomena. Ozone and other particulate concentrations appear to be higher at weekends than during the week contrary to expectations. Similarly, diurnal temperature range is known to be different at the weekend, mostly higher, Forster and Solomon (2003). Mortality from murder, by SIDS, and in hospital patients is also subject to a weekend effect Wiersema (1996), Spiers and Guntheroth (2005), and Washington Post (2004). Many of these phenomena have only partial explanations.
} 
grounds, as is well explained in Levy (2006), see also Post (2003). According to Levy (2006), the criterion of stochastic dominance is the natural economic criterion to apply to investors who follow the expected utility paradigm. In this approach, there are a hierarchy of criteria: First order dominance applies to non-satiable individuals, Second order dominance applies to non-satiable and risk averse individuals. Third and higher order dominance can be defined for individuals with additional restrictions on their utility functions. The second order dominance criterion is perhaps the most central concept for financial applications as risk aversion seems natural. In our context, if Monday returns are second order stochastically dominated by the other weekday returns, then no risk averse individual (who is also a maximizer of expected utility) would prefer Monday returns to the other weekday returns. In this case, we shall say that the Monday effect exists in the sense of the second order SD. The traditional notion of the Monday effect is based on comparing mean returns by dummy regression analysis. However, given the considerable evidence of non-normality of stock returns, relying purely on expected returns to assess investment strategies may not be appropriate because those large difference in expected returns may be compensated by differences in risk. This view was taken by Seyhun (1993) in his exploration of the January effect. He argues that the SD approach provides a clearer test of the market efficiency hypothesis by taking account of omitted risk factors. Therefore, we believe that our general notion of the Monday effect based on the SD criterion is more powerful than the traditional notion. Note that a necessary condition for first order and second order stochastic dominance is majorization in mean, but this is not generally sufficient. Even if domination of the mean is found this does not imply that all non-satiable risk averse investors would prefer not to choose that asset. Seyhun (1993) provides an analysis of first, second, and third order stochastic dominance of January returns, and finds that January returns generally stochastically dominate the returns from other months. However, he did not provide a statistical basis for interpreting his results other than a small simulation study.

We consider observations on US, UK, and Japanese major stock indexes during the period $1 / 1 / 1970$ - 12/31/2004. In particular, we consider the Dow Jones Industrial Average (DJIA), the S\&P 500, the NASDAQ, the Russell 2000, the FTSE 100, and the Nikkei 225. We also consider the CRSP indexes, value and equal weighted, with and without dividend payments over the same period. This covers both small cap and large cap indexes. The time period covers more recent events than earlier studies. To test the general notion of the Monday effect, we shall employ modified versions of the test of Linton, Maasoumi and Whang (2005) (hereafter LMW). This is a consistent test of the hypothesis according to the usual definitions, and indeed has non trivial power against a large class of local alternatives.

The main findings of this paper can be summarized as follows. We find strong evidence of a Monday effect under this stronger criterion in some cases. Specifically, we find evidence of the 
second order dominance of Monday by other days for the full sample of DJIA and S\&P500. There is strong evidence of first order dominance in the CRSP indexes, especially for the equal weighted ones. There is less evidence of dominance in the subsample from 1988 -2004 for the DJIA and S\&P500 as well as the value weighted CSRP indexes. However, there is evidence of second order dominance in the later period for the NASDAQ and the Nikkei 225. The very small cap Russell 2000 shows evidence of first order domination for the later period. We also find evidence that the effect is even stronger in the second half of the month and on days when the previous Friday return was negative. This is consistent with the findings of Wang, Li, and Erickson (1997) and Mehdian and Perry (2001).

Our defence against the data snooping critique of Sullivan, Timmerman, and White (2001) and Hansen, Lunde, and Nason (2005) is that we are using a different economic criterion that is more acceptable from a theoretical point of view than theirs. We are therefore using a different statistical technique quite unrelated to the regression and Sharpe ratio approaches they looked at and that others have followed. Indeed, our hypothesis is stronger than theirs since it concerns the whole distribution. Also, we are using a large number of different indexes, large cap and small cap, domestic and international, and over a more recent period than they did. So the combination of evidence seems quite strong. There is also a question as to what is the relevant universe to define for the data snooping test, and whether in practice statisticians really are searching over so many obviously absurd potential anomalies.

The rest of this paper is organized as follows. Section 2 defines the hypotheses of interest and defines the test statistics. Section 3 presents the empirical results and Section 4 concludes.

\section{Monday Effect and Stochastic Dominance}

The theory of stochastic dominance offers a decision-making rule under uncertainty provided the decision-maker's utility function share certain properties. It was first established by Hadar and Russell (1969), Hanoch and Levy (1969), and Rothschild and Stiglitz (1970). The stochastic dominance rule is more satisfactory from an economic theory point of view than the commonly used mean-variance rule since it is defined with reference to a much larger class of utility functions/return distributions. ${ }^{2}$ We first briefly define the criteria of stochastic dominance.

\subsection{Concepts of Stochastic Dominance}

Let $X_{1}$ and $X_{2}$ be two random variables (or returns/prospects). Let $U_{1}$ denote the class of all von Neumann-Morgenstern type utility functions, $u$, such that $u^{\prime} \geq 0$, (increasing). Also, let $U_{2}$ denote

\footnotetext{
${ }^{2}$ Levy (2006) is an excellent reference for further details on stochastic dominance.
} 
the class of all utility functions in $U_{1}$ for which $u^{\prime \prime} \leq 0$ (concavity), and let $\mathcal{U}_{3}$ be the set of functions in $\mathcal{U}_{2}$ for which $u^{\prime \prime \prime} \leq 0$. Let $F_{1}(x)$ and $F_{2}(x)$ be the cumulative distribution functions of $X_{1}$ and $X_{2}$, respectively. Then, we define

Definition $1 X_{1}$ First Order Stochastic Dominates $X_{2}$, denoted $X_{1} \succeq_{F S D} X_{2}$, if and only if either:

(1) $E\left[u\left(X_{1}\right)\right] \geq E\left[u\left(X_{2}\right)\right] \quad$ for all $u \in \mathcal{U}_{1}$, with strict inequality for some $u$; Or

(2) $F_{1}(x) \leq F_{2}(x) \quad$ for all $x$ with strict inequality for some $x$.

Definition $2 X_{1}$ Second Order Stochastic Dominates $X_{2}$, denoted $X_{1} \succeq_{S S D} X_{2}$, if and only if either:

(1) $E\left[u\left(X_{1}\right)\right] \geq E\left[u\left(X_{2}\right)\right] \quad$ for all $u \in \mathcal{U}_{2}$, with strict inequality for some $u$; Or

(2) $\int_{-\infty}^{x} F_{1}(t) d t \leq \int_{-\infty}^{x} F_{2}(t) d t$ for all $x$ with strict inequality for some $x$.

The third order dominance criteria is defined likewise. Any ordering of outcomes derived from a specific utility function in $\mathcal{U}_{1}, \mathcal{U}_{2}$, and $\mathcal{U}_{3}$ will not enjoy general acceptance. This is a major reason for adopting the SD criterion. Levy (2006) gives the following simple example. Suppose that $X_{1} \in\{1,2\}$ with equal probability on each outcome and $X_{2} \in\{2,4\}$ likewise. Then $E\left(X_{1}\right)<E\left(X_{2}\right)$ but $\operatorname{var}\left(X_{1}\right)<\operatorname{var}\left(X_{2}\right)$ so that there exists a mean/variance optimizer who would prefer $X_{1}$ over $X_{2}$. However, this cannot make economic sense because $X_{1} \leq X_{2}$ with probability one.

Let $D_{k}^{(1)}(x)=F_{k}(x)$ and then recursively define

$$
D_{k}^{(s)}(x)=\int_{-\infty}^{x} D_{k}^{(s-1)}(t) d t, \quad s \geq 2
$$

for each $k$. We say that $X_{1}$ Stochastically Dominates $X_{2}$ at order $s$, if $D_{1}^{(s)}(x) \leq D_{2}^{(s)}(x)$ for all $x$ with strict inequality for some $x$, see LMW for a further discussion on the different concepts of stochastic dominance. Davidson and Duclos (2000) offer a very useful characterization of any SD order and tests.

In our case we have $k=1,2,3,4,5$ days of the week, and so we need a slight generalization of the above definition designed for two variables, and we shall adopt the stochastic maximality approach initiated by McFadden (1989) and Klecan, McFadden, and McFadden (1991).

\subsection{The Hypotheses of Interest and Test Statistics}

Let $X_{1}$ denotes the Monday returns and $X_{2}, \ldots, X_{5}$ denote the other weekday (i.e., Tuesday,..., Friday, respectively) returns. The hypothesis that is usually tested in the literature is that $E\left(X_{j}\right)=E\left(X_{k}\right)$ for $j, k=1, \ldots, 5$ against the alternative that $E\left(X_{j}\right) \neq E\left(X_{k}\right)$ for some $j, k \in\{1, \ldots, 5\}$. This is usually performed by a Wald or $\mathrm{F}$ test from a regression of daily returns on daily dummies. Another test that is commonly used is of the hypothesis that $E\left(X_{1}\right)=0$ against the one-sided alternative 
that $E\left(X_{1}\right)<0$, which can be done with a t-test on the Monday coefficient. ${ }^{3}$ Neither approach really captures the essence of the Monday effect as either the alternative is too general or the null is too strong. We think that the hypothesis of a Monday effect the literature has in mind is that

$$
E\left(X_{1}\right) \leq E\left(X_{j}\right), j=2, \ldots, 5
$$

i.e., mean returns on Monday are lower than mean returns on other days of the week. Wolak (1987) develops a statistic suitable for testing this hypothesis against its general alternative in a regression context. Our purpose is to test the following related hypothesis

$$
\mathbf{H}_{0}^{1} \text { : Monday is (stochastically) dominated by all other weekdays, }
$$

with alternative the negation of the null. This hypothesis is stronger than (1), i.e., (1) is necessary but not sufficient for (2). Therefore, if (2) is true, then so is (1).

To provide a more nuanced investigation of the Monday effect, we consider the following additional null hypotheses: $\mathbf{H}_{0}^{2}$ :Monday dominates at least one of the other weekdays; $\mathbf{H}_{0}^{3}$ :Monday dominates all other weekdays; $\mathbf{H}_{0}^{4}$ :Monday is dominated by at least one of the other weekdays; $\mathbf{H}_{0}^{5}$ :There exists at least one day that dominates all others; $\mathbf{H}_{0}^{6}$ :There exists at least one day that is dominated by all others; $\mathbf{H}_{0}^{7}$ :Either Monday or the rest of the weekdays dominates the other. The alternative hypotheses are negations of the null hypotheses. Note that the Monday effect is compatible with the null hypotheses $H_{0}^{1}, H_{0}^{4}, H_{0}^{6}$, and $H_{0}^{7}$. On the other hand, the reverse Monday effect is compatible with $H_{0}^{2}, H_{0}^{3}, H_{0}^{5}$, and $H_{0}^{7}$. For completeness we also include the (rather strong) hypothesis of equal distributions, which is consistent with the EMH and therefore inconsistent with either the Monday or the reversed Monday effects, i.e., $\mathbf{H}_{0}^{8}$ : All days have the same distribution of returns. We consider these different null hypotheses because they provide additional shades of meaning. Hypothesis $H_{0}^{1}$ is the main focus, $H_{0}^{4}$ is a weaker form, while $H_{0}^{6}$ and $H_{0}^{7}$ contain ambiguity about which day is special, likewise with $H_{0}^{2}, H_{0}^{3}, H_{0}^{5}$, and $H_{0}^{7}{ }^{4}$

We next express the above hypotheses using functionals of the distribution functions of the returns. Let $\mathcal{X}$ denote the support of $X_{k}^{\prime} s$ for $k=1, \ldots, 5$, and let $s=1,2,3$ represent the order of stochastic dominance. For each $k, l=1, \ldots, 5, s=1,2,3$, and $x \in \mathcal{X}$, let $\Delta_{k, l}^{(s)}(x)=D_{k}^{(s)}(x)-D_{l}^{(s)}(x)$.

\footnotetext{
${ }^{3}$ Kamara (1997) and Mehdian and Perry (2001) also test the hypothesis $E\left(X_{1}\right)=\sum_{j=2}^{5} E\left(X_{j}\right) / 4$ versus $E\left(X_{1}\right)<$ $\sum_{j=2}^{5} E\left(X_{j}\right) / 4$

${ }^{4}$ This ambiguity can capture other day of the week effects as have been found in some international markets, Martikainen and Puttonen (1996).
} 
Then define:

$$
\begin{aligned}
& d_{1 s}^{*}=\max _{k \neq 1} \sup _{x \in \mathcal{X}} \Delta_{k, 1}^{(s)}(x) ; d_{2 s}^{*}=\min _{k \neq 1} \sup _{x \in \mathcal{X}} \Delta_{1, k}^{(s)}(x) \\
& d_{3 s}^{*}=\max _{k \neq 1} \sup _{x \in \mathcal{X}} \Delta_{1, k}^{(s)}(x) ; d_{4 s}^{*}=\min _{k \neq 1} \sup _{x \in \mathcal{X}} \Delta_{k, 1}^{(s)}(x) \\
& d_{5 s}^{*}=\min _{k} \max _{l \neq k} \sup _{x \in \mathcal{X}} \Delta_{k, l}^{(s)}(x) ; d_{6 s}^{*}=\min _{k} \max _{l \neq k} \sup _{x \in \mathcal{X}} \Delta_{l, k}^{(s)}(x) \\
& d_{7 s}^{*}=\min _{k}\left\{\max _{k \neq 1} \sup _{x \in \mathcal{X}} \Delta_{k, 1}^{(s)}(x), \max _{k \neq 1} \sup _{x \in \mathcal{X}} \Delta_{1, k}^{(s)}(x)\right\} ; d_{8 s}^{*}=\max _{k \neq 1} \sup _{x \in \mathcal{X}}\left|\Delta_{1, k}^{(s)}(x)\right|
\end{aligned}
$$

The null and alternative hypotheses in $\mathbf{H}_{0}^{1}-\mathbf{H}_{0}^{8}$ can now be stated as:

$$
\mathbf{H}_{0}^{j}: d_{j s}^{*} \leq 0 \text { vs. } \mathbf{H}_{1}^{j}: d_{j s}^{*}>0 \text { for } j=1, \ldots, 8
$$

We next discuss how to compute test statistics based on a data set $\left\{X_{k t}: t=1, \ldots, N, k=\right.$ $1, \ldots, 5\}$. The test statistics we consider are based on the empirical analogues of (3)-(6). For example, for the null hypothesis $H_{0}^{1}$, we define the test statistic to be

$$
D 1_{N}^{(s)}=\max _{k \neq 1} \sup _{x \in \mathcal{X}} \sqrt{N}\left[\bar{D}_{N}^{(s)}\left(x ; \bar{F}_{k}\right)-\bar{D}_{N}^{(s)}\left(x ; \bar{F}_{1}\right)\right]
$$

where

$$
\bar{D}_{N}^{(s)}\left(x ; \bar{F}_{k}\right)=\frac{1}{N(s-1) !} \sum_{i=1}^{N} 1\left(X_{k i} \leq x\right)\left(x-X_{k i}\right)^{s-1} \text { for } k=1, \ldots, 5
$$

The other test statistics $D 2_{N}^{(s)}, \ldots, D 8_{N}^{(s)}$ are defined analogously. The supremum in (8) can be approximated by the maximum over a dense grid, see LMW for further discussion.

Rejection of each hypothesis is based on large positive values of the test statistic. Under suitable regularity conditions as in LMW (Assumptions 1-3), we can show that the test statistics converge weakly to functionals of a Gaussian process. However, since the limiting distributions depend on unknown true distributions of $X_{k}^{\prime} s$, the asymptotic critical values can't be tabulated once and for all. Therefore, as in LMW, we suggest to estimate the asymptotic p-values using resampling schemes such as bootstrapping and subsampling. See Horowitz (2000) for a discussion of the general issues involved in resampling time series.

First, we describe the subsampling procedure. Let $W_{N}$ denote any of the test statistics $D j_{N}^{(s)}$ for $j=1, \ldots, 8, s \geq 1$. Then,

(i) Calculate the test statistic $W_{N}$ using the original full sample $\mathcal{W}_{N}=\left\{Z_{i}=\left(X_{1 i}, \ldots, X_{5 i}\right)^{\top}\right.$ : $i=1, \ldots, N\}$.

(ii) Generate subsamples (or blocks) $\mathcal{W}_{N, b, i}=\left\{Z_{i}, \ldots, Z_{i+b-1}\right\}$ of size $b$ for $i=1, \ldots, N-b+1$. 
(iii) Compute test statistics $W_{N, b, i}$ using the subsamples $\mathcal{W}_{N, b, i}$ for $i=1, \ldots, N-b+1$.

(iv) Approximate the asymptotic p-value by

$$
p_{S, b}=\frac{1}{N-b+1} \sum_{i=1}^{N-b+1} 1\left(W_{N, b, i}>W_{N}\right) .
$$

The choice of the subsample size can be data-dependent and should satisfy $b \rightarrow \infty$ and $b / N \rightarrow 0$ as $N \rightarrow \infty$, see LMW for details.

On the other hand, the (re-centered overlapping) bootstrap procedure can be described as follows:

(i) Same as Step (i) above.

(ii) Same as Step (ii) above.

(iii) Generate the bootstrap sample $\mathcal{W}_{N}^{*}=\left\{Z_{i}^{*}: i=1, \ldots, N\right\}$ by sampling the $N-b+1$ overlapping blocks and laying them end-to-end in the order sampled. Repeat this $M$-times, where $M$ is the number of the bootstrap samples.

(iv) Compute the recentred test statistic $W_{N}^{*}$ using the bootstrap sample $\mathcal{W}_{N}^{*}$. For example, for the test $D 1_{N}^{(s)}$ define

$$
W_{N}^{*}=: D 1_{N}^{(s) *}=\max _{k \neq 1} \sup _{x \in \mathcal{X}} \sqrt{N}\left[\bar{D}_{N}^{(s) *}\left(x ; \bar{F}_{k}\right)-\bar{D}_{N}^{(s) *}\left(x ; \bar{F}_{1}\right)\right]
$$

where

$$
\begin{gathered}
\bar{D}_{N}^{(s) *}\left(x ; \bar{F}_{k}\right)=\frac{1}{N(s-1) !} \sum_{i=1}^{N}\left\{1\left(X_{k i}^{*} \leq x\right)\left(x-X_{k i}^{*}\right)^{s-1}-\omega(i, b, N) 1\left(X_{k i} \leq x\right)\left(x-X_{k i}\right)^{s-1}\right\}, \\
\omega(i, b, N)= \begin{cases}i / b & \text { if } i \in[1, b-1] \\
1 & \text { if } i \in[b, N-b+1] \\
(N-i+1) / b & \text { if } i \in[N-b+2, N] .\end{cases}
\end{gathered}
$$

Repeat this $M$-times.

(v) Approximate the asymptotic p-value by calculating the proportion of $W_{N}^{*}$ 's that exceeds $W_{N}$ in the $M$ repetitions.

Instead of this overlapping block bootstrap, we can also use the non-overlapping block bootstrap of Carlstein (1986) or the stationary bootstrap of Politis and Romano (1994), see Lahiri (1999) for a recent survey. As in subsampling, the length $b$ of the blocks should satisfy $b \rightarrow \infty$ and $b / N \rightarrow 0$ as $N \rightarrow \infty$. LMW prove that subsampling provides consistent critical values under very weak conditions 
allowing for cross-sectional dependence amongst the outcomes and weak temporal dependence. LMW also provide simulation evidence on the small sample performance of their test statistics in a variety of sampling schemes. They show that the finite sample performance is quite good even for sample sizes of 500. In our empirical work below we use both the bootstrap and the subsampling algorithms to compute critical values.

\section{Empirical Results}

\subsection{Data}

We use a number of end of the day indexes. The Dow Jones Industrial Average (DJIA) and the S\&P 500 cover the period 1/1/1970 to 12/31/2004. The sample period for the NASDAQ and the Russell 2000 is from 1/1/1988 to 12/31/2004. The CRSP indexes, EWX (equal weighted without dividends), VWX (value weighted without dividends), EWD (equal weighted with dividends), and VWD (value weighted with dividends) cover exactly the same period. We also examine the Nikkei 225 and the FTSE 100 during the period 1/1/1990 to 12/31/2004. This extends the period of Steeley (2001) who analyzed the FTSE 100 over 1/4/1991 - 1/8/1998. To investigate the structural change effect after the 1987 crash (see Fortune (1998), Median and Perry (2001), and Brusa, Liu and Schulman (2003)), we analyze the DJIA, S\&P 500, and CRSP indexes for two sub-periods, i.e. pre-1988 and post-1988. We excluded weeks containing holidays in order to accommodate general dependence amongst the returns in each week. The number of observations are: DJIA, S\&P 500, EWX, EWD, VWX, and VWD (793, pre-1988; 744, post-1988), NASDAQ and Russell 2000 (744), FTSE 100 (677) and Nikkei 225 (613). Daily returns are calculated as: $R_{i}=\ln \left(P_{i} / P_{i-1}\right)$, where $R_{i}$ is the daily return on day $i$, $P_{i}$ and $P_{i-1}$ are closing values of stock index on days $i$ and $i-1$ respectively. The CRSP EWD and VWD data include dividends in the definition of returns, whereas the EWX and VWX exclude them. Lakonishok and Smidt (1989) included dividend returns in the DJIA and found that for example in $198142 \%$ of dividend returns occurred on a Monday. However, they later found that adjusting for dividend returns makes very little difference to the analysis. Steeley (2001) found something similar in the FTSE. We include both with and without dividend indexes for the CRSP data to check this. 


\section{$3.2 \quad$ Results}

\subsubsection{Regression Analysis}

To compare our methods with the existing results, we first consider the traditional method that has been frequently used in the literature. That is, consider the linear regression

$$
R_{i}=\alpha_{1} D_{1 i}+\alpha_{2} D_{2 i}+\alpha_{3} D_{3 i}+\alpha_{4} D_{4 i}+\alpha_{5} D_{5 i}+\varepsilon_{i}
$$

where $R_{i}$ is the stock return, $D_{1 i}$ is a dummy variable which takes the value 1 if day $i$ is a Monday, and 0 otherwise, $D_{2 i}$ is a dummy variable which takes the value 1 if day $i$ is a Tuesday, and 0 otherwise; and so forth.

Table 1.1 provides the OLS estimates for all indexes and subperiods. The standard errors are Newey-West (1987)'s HAC estimates with data dependent truncation. W1 is the Wald test statistic for the null hypothesis $\mathbf{H}_{0}: \alpha_{1}=\alpha_{2}=\alpha_{3}=\alpha_{4}=\alpha_{5}$, and W2 is that for $\mathbf{H}_{0}: \alpha_{1} \leq \alpha_{2}, \alpha_{1} \leq$ $\alpha_{3}, \alpha_{1} \leq \alpha_{4}, \alpha_{1} \leq \alpha_{5}$. The alternatives are just the negations. The test of W2 is due to Wolak (1987) and our use appears new in this literature. The apparent Monday effect based on mean returns exists in DJIA (1970-1987), S\&P 500 (1970-1987), and Russell 2000 (1988-2004), which is consistent with the literature. Note that the post-1988 DJIA Monday returns are significantly positive as was documented elsewhere. However, since W1 is not significant, this does not support the reverse Monday effect in this period, contrary to Median and Perry (2001) and Brusa, Liu and Schulman (2003). Also, unlike the Russell 2000, the Monday effect does not seem to exist on the NASDAQ. The Nikkei 225 shows that Monday returns are significantly negative on average but the W1 indicates that they are not significantly different from the other weekday returns. As in Steely (2001), the Monday effect is not significant for the FTSE. ${ }^{5}$ Regarding the CRSP indexes, the equal weighted series show the stronger evidence of Monday effect for the full sample as well as both subsamples: in all such cases W1 is rejected but W2 is not rejected. Furthermore, the coefficient on Monday is always negative. The value weighted CRSP series show less evidence since W1 is not rejected for 1988-2000. The coefficient on Monday in those cases is also positive; however, it is still lower than the coefficient on all other days of the week.

$$
\text { ***Table } 1.1 \text { here*** }
$$

Daily stock return data are known to have quite heavy tails and so the linear regression results may be suspect. ${ }^{6}$ Specifically, least squares methods do not have bounded influence and so outliers or heavy tails can make the estimator inconsistent. Even when the estimator itself is consistent,

\footnotetext{
${ }^{5}$ See Steeley (2001, Table 2) for comparison.

${ }^{6}$ All the data series strongly fail Kolmogorov-Smirnov and Jarque-Bera tests for normality.
} 
the standard errors require even higher moments to exist, especially in the dependent heterogeneous environments that we would like to accommodate here, for consistency. This is a particularly salient issue here as the 1987 crash produced a very large negative return, and on a Monday. Therefore, we redid the analysis using the quantile regression techniques due to Koenker and Bassett (1978) that are robust to heavy tailed errors and outliers. In Table 1.2 we report the results of linear quantile regressions for quantiles $q=0.25,0.5,0.75$ for the CRSP indexes; in the unpublished appendix, Cho, Linton and Whang (2006) we give the results for the other indexes. The results at the median are generally similar to those of the mean regression. Monday generally has the smallest coefficient except in the 1988-2004 period for the DJIA and SP500 when the reverse phenomenon is observed. This finding also holds for the $q=0.25$ quantile, but is reversed in many cases for the $q=0.75$ quantile then the Monday coefficient is actually largest for the Nikkei, the FTSE, S\&P500 for 1988-2004, and the DJIA for 1970-2004 and 1988-2004 (this is not true for the CRSP indexes, although the value weighted series show a high but not highest coefficient in this case). For the equal weighted CRSP indices the hypothesis of equal coefficients is strongly rejected at all quantiles and for all subperiods. For the other series the $\mathrm{p}$ values are highest for the later subperiod and $q=0.75$, and generally the pattern is similar to that for the least squares estimates. This is supportive of the idea that the calendar effect is not just a phenomenon about the mean of returns.

\section{***Table 1.2 here ${ }^{* * *}$}

To continue the theme of the last paragraph we investigated whether volatility is subject to a calendar effect. In Table 1.3 we report the results of linear regression using the squared residuals from the basic linear regression (11) as the dependent variable, here we just report the results for the CRSP indexes, the full results are found in the unpublished appendix, Cho, Linton and Whang (2006). The coefficient on the Monday dummy is always the highest, sometimes significantly so, indicating that the weekend is associated with higher volatility. This may be as expected from the calendar time hypothesis of French (1980). However, the level of volatility is never three times that of the other days: for the DJIA 1970-1987 and the CRSP indexes it is twice the level of the other days, whereas for the NASDAQ there seems to be almost no difference in the level of volatility over the weekend versus other days (the Wald test of the calendar time hypothesis is rejected for all series). The Wald tests for equality of variance indicate some statistical significance to these differences especially for the CRSP equally weighted indexes. For both the DJIA and the S\&P500, the volatility effect seems to decline in the later period relative to the earlier period.

***Table 1.3 here ${ }^{* * *}$ 
Many studies have found a January effect and other monthly level differences in stock returns, see Seyhun (1993) for example. Therefore, it is important to test whether the Monday effect is affected by controlling for month effects. In the unpublished appendix, Cho, Linton and Whang (2006), we report results of a regression where we add in monthly dummies to the basic linear specification (11). The results for the Wald tests of the main hypothesis are almost identical to those in Table 1.1., so that there is evidence of a Monday effect in many cases. Interestingly, apart from the DJIA, 1988-2004 and the CRSP equal weighted indexes, there appears to be little evidence of a monthly seasonal after controlling for days of the week. The goodness of fit of the regression does rise although not substantially so after accounting for the number of parameters. We also ran a regression where we add in year dummies as well to the basic linear specification (11). Again the results for the main Wald test are similar. Apart from the Nikkei (and then only at 0.06), there does not appear to be evidence of a year effect. The goodness of fit is worse after accounting for the number of parameters.

In conclusion, there appears to be evidence for a Monday effect in some of the stock indexes at least for some of the time, but it is somewhat sensitive to period and the overall effect is more complex than can be captured in a simple mean regression specification. This is one reason why we turn to the distributional analysis involved in the SD criteria. The other reason is of course the economic case we laid out earlier.

\subsubsection{The Stochastic Dominance Approach}

In the unpublished appendix, Cho, Linton and Whang (2006), we report a full set of results involving p-values for tests of 1st, 2nd, and 3rd order dominance corresponding to the eight different hypotheses for each of the series in the full sample and subsample and cut according to various parts of the month etc. $^{7}$ We give results for bootstrap and subsampling implementations. Here, we focus on a subset of the results and provide a summary of the more detailed work. Specifically, in Table 2 we give the subsampling results. ${ }^{8}$ As noted by LMW, the choice of the subsample size $b$ is important but rather difficult. They propose a number of practical criteria for choosing $b$. In our application, we report the median of the $p$-values from 30 different subsample sizes in the range $\left[N^{0.3}, N^{0.7}\right]$. We do not have space here to discuss the results for each individual hypothesis: our summary of the results informally aggregates across these separate results. We find strong evidence of a Monday effect under this stronger criterion in most cases. Specifically, we find evidence of the second order dominance of Monday by other days for the full sample of DJIA and S\&P500. The CRSP data provides even stronger evidence of first order dominance for the same period for all four indexes.

\footnotetext{
${ }^{7}$ Note that the Monday effect is compatible with the null hypotheses $H_{0}^{1}, H_{0}^{4}, H_{0}^{6}$, and $H_{0}^{7}$. On the other hand, the reverse Monday effect is compatible with $H_{0}^{2}, H_{0}^{3}, H_{0}^{5}$, and $H_{0}^{7} . H_{0}^{8}$ is compatible with neither.

${ }^{8}$ The results using bootstrapping agree quite closely with those based on subsampling.
} 
The evidence of dominance in the subsample from 1988 -2004 for the S\&P500 and Dow Jones is much weaker and there is even some evidence of reversal. However, the CRSP data still support the hypothesis of dominance in the later subsample although the evidence is much weaker especially for the value weighted series without dividends. During the same period there is evidence of second order dominance for the NASDAQ and the Nikkei 225. The very small cap Russell 2000 shows evidence of first order domination for this later period. Finally, the FTSE (which is over the later period) shows only weak evidence of dominance at the third order.

\section{***Table 2 here H** $^{* *}$}

The p-values do not give any idea of the economic magnitude of the differences in outcomes. We show in Figure 1 the empirical c.d.f.'s and s.d.f.'s (integrated c.d.f.'s) of the five days for the equal weighted without dividends CRSP data. The Monday c.d.f. lies above the c.d.f.'s for the other days until a very high level of returns is reached, when the Tuesday distribution crosses it. The other distributions are always well below the Monday distribution. None of the other s.d.f.'s cross the Monday s.d.f. at all. This shows that bad news tends to be much worse on Mondays than on other days. Furthermore, the magnitude of the difference, measured by the horizontal distance between the distribution functions, is quite large.

Motivated by work of Wang, Li, and Erickson (1997) and Mehdian and Perry (2001), we report, in Cho, Linton and Whang (2006), additional results for: the first three weeks of the month; the second half of the month; a positive preceding Friday; a negative preceding Friday. We summarize these results along with those of Table 2 in a table below. We find evidence that the effect is even stronger when the previous Friday return was negative. This effect generally persists across subsamples although the evidence is inconclusive for the Dow Jones and S\&P 500 during the later period on days when the previous Friday return was negative. This is broadly in agreement with earlier work, for example Mehdian and Perry (2001) who also found strong effects but effects that did not persist for large cap indexes. We also find that the effect is very strong in the second half of the month and that this effect does persist for both large cap and small cap indexes in the later period. We find that when returns on Friday were positive the ordering in many cases reverses (although not for the CRSP series). On the other hand, the first half of the month continues to show predominantly that Monday returns are dominated by other days of the week although the evidence on this is weaker than for the full sample. This is generally consistent with the findings of Wang, Li, and Erickson (1997) and Mehdian and Perry (2001). Since we have used more data and a different criterion, we find this compelling confirmation of their findings. We remark, however, that these results are statistically harder to support because the implicit sample sizes are less and so small sample effects may make these results a bit questionable. 


\begin{tabular}{l|c|c|c|c|c}
\multicolumn{2}{|c}{ Summary of Tables } & \\
stock indexes & whole month & weeks 1-3 & 2nd half & + Friday & - Friday \\
\hline \hline a. DJIA (pre-1988) & FSD & SSD & FSD & FSD rev & FSD \\
b. DJIA (post-1988) & FSD rev & FSD rev & FSD & FSD rev & inconclusive \\
c. DJIA (full sample) & SSD & inconclusive & FSD & FSD rev & SSD \\
d. S\&P 500 (pre-1988) & FSD & FSD & FSD & FSD rev & FSD \\
e. S\&P 500 (post-1988) & inconclusive & FSD rev & FSD & FSD rev & inconclusive \\
f. S\&P 500 (full sample) & SSD & inconclusive & FSD & FSD rev & FSD \\
g. NASDAQ (1988-2004) & SSD & inconclusive & FSD & FSD rev & FSD \\
h. RUSSELL 2000 (1988-2004) & FSD & inconclusive & FSD & inconclusive & FSD \\
i. FTSE 100 (1990-2004) & TSD & FSD rev & FSD & FSD rev & FSD \\
j. NIKKEI 225 (1990-2004) & SSD & SSD & SSD & FSD rev & FSD \\
k. VWD (1970-1987) & FSD & FSD & FSD & FSD rev & FSD \\
l. VWD(1988-2004) & inconclusive & FSD rev & FSD & FSD rev & FSD \\
m. VWD (1970-2004) & FSD & inconclusive & FSD & FSD rev & FSD \\
n. VWX (1970-1987) & FSD & FSD & FSD & inconclusive & FSD \\
o.VWX (1988-2004) & inconclusive & FSD rev & FSD & FSD rev & FSD \\
p. VWX (1970-2004) & FSD & inconclusive & FSD & FSD rev & FSD \\
q. EWD (1970-1987) & FSD & SSD & FSD & inconclusive & FSD \\
r. EWD (1988-2004) & FSD & SSD & FSD & inconclusive & FSD \\
s. EWD (1970-2004) & FSD & FSD & FSD & weak rev & FSD \\
t. EWX (1970-1987) & FSD & FSD & inconclusive & FSD \\
u. EWX (1988-2004) & FSD & FSD & inconclusive & FSD \\
v. EWX (1970-2004) & inconclusive & FSD \\
Notes. + (-) Friday means positive & Fegative) returns on previous & Friday. FSD (SSD) [TSD] means First,
\end{tabular}

(Second), [Third] order dominance of Monday returns. rev abbreviates reverse.

In conclusion, our methodology supports the view that there is a Monday effect in many indexes, and in some cases quite a strong one. This evidence should be considered quite convincing because the null hypothesis is very strong and the result is obtained on many different series. Of course it is strongest in those indexes that are more broadly based like the CRSP indexes, suggesting that capitalization plays an important role in the magnitude and persistence of the effect. The fact that the effect is reversed or weakened for some large cap and international series is also interesting and needs explanation. Note that our evidence is robust to a small number of large observations unlike the previously reported regression results. 


\section{Concluding Remarks}

The results using stochastic dominance criteria confirm earlier findings of a Monday effect for many series over the full sample. This effect has weakened for some large cap series like the DJIA and the S\&P500 post 1987, but remains strong for more broadly based indexes. The affect is attenuated or enhanced by other conditioning variables but still represents a puzzle to advocates of EMH. Our analysis is based on a more generally acceptable approach to ranking investments than just looking at the mean as was implicit in the earlier regression approach. The hypothesis we test is stronger than the usual one and our results suggest that regardless of investors' attitudes to risk, degree of risk aversion, or seasonal variations in risk premia, Monday returns were too low to be equilibrium returns. This cannot be attributed to omitted risk factors. However, we caution that the methodology we have used generally requires quite large sample sizes and so there are grounds for caution regarding the main findings in terms of the statistical significance.

What are the implications for Asset Pricing? As Fama (1991) puts it, "market efficiency per se is not testable. It must be tested jointly with some model of equilibrium, an asset-pricing model." Therefore, when we find anomalous evidence on the behaviour of returns, the way it should be split between market inefficiency or a bad model of market equilibrium is not clear.

The evidence of stochastic dominance of Monday returns by other weekdays could be combined with behavioral theories from the psychology literature to create new asset-pricing theories that combine economic equilibrium concepts with psychological concepts to create an improved asset-

pricing model. For instance, the summary table reveals that there is strong evidence of a Monday effect on days when the previous Friday return was negative. Market efficiency asserts that apparent overreaction to information is about as frequent as underreaction, a statement that seems to be refuted by the above evidence. This underreaction of stock prices is consistent with the behavioural model proposed by Barberis, Shleifer, and Vishny (1998), to explain how the judgment biases- the representativeness bias of Kahneman and Tversky (1982) and conservatism attributed to Edwards (1968)- of investors can produce overreaction to some events and underreaction to others. This model, however, performs poorly in explaining the other anomalies reported in the literature. This suggests the need for an alternative model that specifies biases in information processing that cause the same investors to under-react to some types of events and over-react to others and also explains the range of observed results better than the simple market efficiency story. 


\section{References}

[1] Barberis, N., A. Shleifer and R. Vishny (1998), "A Model of investor sentiment", Journal of Financial Economics 49:307-345.

[2] Brusa, J., P. Liu and C. Schulman (2003), "The Weekend and 'Reverse' Weekend Effects: An Analysis by Month of the Year, Week of the Month, and Industry," Journal of Business Finance and Accounting, Vol. 30, pp. 863-890.

[3] Carlstein, E. (1986), "The use of subseries values for estimating the variance of a general statistic from a stationary sequence," The Annals of Statistics 14, 1171-1179.

[4] Cho, Y.H., O. Linton, and Y.J. Whang (2006). Are there Monday effects in Stock Returns: A Stochastic Dominance Approach. Additional Appendices. Available from o.linton@lse.ac.uk.

[5] Coutts, J. A. and P. A. Hayes, 1999, " The Weekend Effect, the Stock Exchange Account and the Financial Times Industrial Ordinary Shares Index: 1987-1994," Applied Financial Economics, Vol. 9, pp.67-71.

[6] Davidson, R., and J.Y. Duclos (2000), "Statistical Inference for stochastic dominance and for the measurement of poverty and inequality", Econometrica 68(6), 1435-1464.

[7] Edwards, W. (1968), "Conservatism in human information processing", in: B. Kleinmutz, ed., Formal representation of human judgement (Wiley, New York) pp. 17-52.

[8] Fama, E. (1991), "Efficient Capital Markets II" The Journal of Finance 46: 1575-1617.

[9] Forster, P.M. de F. and S. Solomon (2003): "Observations of a "weekend effect," in diurnal temperature range," www.pnas.org/cgi/doi/10.073/pnas.2034034100.

[10] Fortune, P., 1998, "Weekends Can Be Rough: Revisiting the Weekend Effect in Stock Prices," Federal Reserve Bank of Boston Working Paper, 98-6.

[11] French, K., 1980, "Stock Returns and the Weekend Effect," Journal of Financial Economics, Vol. 8, pp.59-69.

[12] Gibbons, M. and P. Hess, 1981, "Day of the Week Effects and Asset Returns," Journal of Business, Vol. 54, pp. 579-596.

[13] Hadar, J. and W. Russell, 1969, "Rules for Ordering Uncertain Prospects," American Economic Review, Vol. 59, pp.25-34. 
[14] Hanoch, G. and H. Levy, 1969, "The Efficiency Analysis of Choices Involving Risk," Review of Economic Studies, Vol.36, pp. 335-346.

[15] Hansen, P.R. Lunde, A., and J.M. Nason (2005): "Testing the significance of calendar effects," Working paper no 2005-2, Federal Reserve Bank of Atlanta.

[16] Horowitz, J.L. (2000), "The Bootstrap," Forthcoming in The Handbook of Econometrics, volume 5.

[17] Kahneman, D., P. Slovic and A. Tversky, eds (1982), Judgement under uncertainty: heuristics and biases (Cambridge University Press).

[18] Kamara, A., (1997): "New evidence on the Monday Seasonal in Stock Returns," Journal of Business 70, 63-84.

[19] Keim, D.B., and R.F. Stambaugh (1984), "A further investigation of the weekend effect in stock returns", Journal of Finance 39: 819-835.

[20] Keim, D.B., and W.T. Ziemba (2000). Security Market Imperfections in World Wide Equity Markets. Cambridge Universtiy Press.

[21] Klecan, L., R. McFadden, and D. McFadden (1991), "A robust test for stochastic dominance," Working paper, Dept. of Economics, MIT.

[22] Koenker, R. and G. Bassett (1978), "Regression Quantiles," Econometrica, 46, 33-50.

[23] Lahiri, S.N. (1999), "Theoretical Comparison of block bootstrap methods", The Annals of Statistics, 27, 386-404.

[24] Lakonishok, J., and M. Levi (1982): "Weekend Effects on Stock Returns: A Note," The Journal of Finance 37, 883-889.

[25] Lakonishok, J., and S. Smidt (1989): "Are seasonal Anomalies Real? A Ninety-Year Perspective," The Review of Financial Studies 1, 403-425.

[26] Levy, H., 2006, Stochastic Dominance, Investment Decision Making under Uncertainty. SSD edition. Springer, Berlin.

[27] Linton, O., E. Maasoumi and Y.-J. Whang, (2005), "Consistent Testing for Stochastic Dominance under General Sampling Schemes," Review of Economic Studies 72, 735-765. 
[28] McFadden, D. (1989), "Testing for stochastic dominance," in Part II of T. Fomby and T.K. Seo (eds.) Studies in the Economics of Uncertainty (in honor of J. Hadar), Springer-Verlag.

[29] Martikainen, T., and V. Puttonen (1996), "Finnish Day-of-the-Week Effects," Journal of Business Finance and Accounting 23, 1019-1032.

[30] Mehdian, S. and M. Perry, 2001, "The Reversal of the Monday Effect: New Evidence from US Equity Markets," Journal of Business Finance and Accounting, Vol. 28, pp. 1043-1065.

[31] Newey, W.K., and K.D. West (1987), "A simple, positive semi-definite, heteroskedasticity and autocorrelation consistent covariance matrix," Econometrica 55, 703-8.

[32] Pettengill, G. (1993). "An Experimental Study of the 'Blue Monday' Hypothesis," Journal of Socio-Economics, 241-257.

[33] Pettengill, G. (2003). "A Survey of the Monday Effect Literature," Quarterly Journal of Business and Economics 42, 3-27.

[34] Politis, D.D., and J.P. Romano (1994), "The stationary bootstrap", Journal of the American Statistical Association, 89, 1303-1313.

[35] Post, T., (2003): "Empirical tests for stochastic dominance efficiency," Journal of Finance 58, 1905-1932.

[36] Rogalski, R.J. (1984): "New Findings Regarding Day-of-the-Week Returns over Trading and Non-Trading Periods: A Note," The Journal of Finance 39, 1603-1614

[37] Rothchild, M. and J. Stiglitz, 1970, "Increasing Risk. I. A Definition," Journal of Economic Theory, Vol. 2, pp.225-243.

[38] Seyhun, H. N., 1993, "Can Omitted Risk Factors Explain the January Effect? A Stochastic Dominance Approach," Journal of Financial and Quantitative Analysis, Vol. 28, pp. 195-212.

[39] Spiers, P.S., and W.G. Guntheroth (2005): "The Effect of the Weekend on the Risk of Sudden Infant Death Syndrom," Pediatrics, April 19th.

[40] Steeley, J. M., 2001, " A Note on Information Seasonality and the Disappearance of the Weekend Effect in the UK Stock Market," Journal of Banking and Finance, Vol. 25, pp. 1941-1956.

[41] Sullivan, R., A. Timmerman, and H. White (2001): "Dangers of data-driven inference: The case of calendar effects in stock returns," Journal of Econometrics 105, 249-286 
[42] Wang, K., Y. Li, and J. Erickson (1997): "A New Look at the Monday Effect," The Journal of Finance 52, 2171-2186.

[43] Washington Post (2004): "The Weekend Effect," July 27th.

[44] Wiersema, B., (1996): "Community Structure and Patterns in Criminal Homicide: Exploring the Weekend Effect," Final Report Grant 94-IJ-CX-0051

[45] Wolak, F. (1987): "An exact test for multiple inequality and equality constraints in the linear regression model" Journal of the American Statistical Association 82, 782-793. 
Table 1-1. OLS Estimates\#

$\begin{array}{lllllllll}\text { Mon. Tue. Wed. Thu. Fri. } & \text { W1 } & \text { W2 } & R^{2} & \bar{R}^{2}\end{array}$

\begin{tabular}{|c|c|c|c|c|c|c|c|c|c|c|c|}
\hline $1970-1987$ & Mean (\%) & -0.116 & 0.027 & 0.073 & 0.015 & 0.033 & $\underline{\text { value }}$ & 9.172 & 0.000 & 0.0036 & 0.0026 \\
\hline ( $\underline{\mathrm{NO}}: 793)$ & $\underline{\mathrm{t} \text {-value }}$ & $-2.144^{* *}$ & 0.801 & 2.161 & 0.460 & 1.079 & prob. & 0.057 & 0.876 & & \\
\hline $1988-2004$ & Mean (\%) & 0.092 & 0.055 & 0.032 & -0.016 & -0.010 & $\underline{\text { value }}$ & 5.578 & 5.056 & 0.0015 & 0.0005 \\
\hline ( $\underline{\mathrm{NO}}: 744)$ & $\underline{\mathrm{t} \text {-value }}$ & $2.423^{* *}$ & 1.608 & 0.893 & -0.435 & -0.256 & prob. & 0.233 & 0.255 & & \\
\hline $1970-2004$ & Mean (\%) & -0.015 & 0.041 & 0.053 & -0.000 & 0.012 & $\underline{\text { value }}$ & 3.557 & 0.000 & 0.0005 & 0.0001 \\
\hline (ㅇ: 1537$)$ & $\underline{\text { t-value }}$ & -0.455 & $1.685^{*}$ & 2.164 & -0.005 & 0.502 & prob. & 0.469 & 0.849 & & \\
\hline
\end{tabular}

b. $S E P 500$

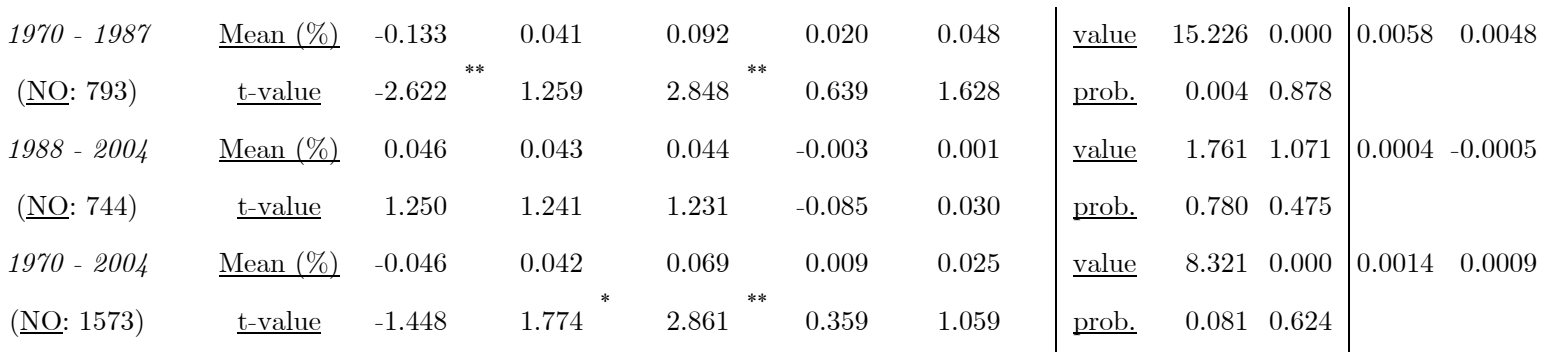

c. NASDAQ

$1988-2004$

(NO: 744)

$\underline{\text { Mean }(\%)}-0.072$

0.013

$0.111 \quad 0.068$

\begin{tabular}{l|lll|ll}
-0.006 & value & 7.241 & 0.000 & 0.0018 & 0.0007
\end{tabular}

$\underline{\underline{\text { t-value }}} \quad-1.356 \quad 0.263$

$2.071^{* *} 1.243$

$-0.130$

$\begin{array}{lll}\text { prob. } & 0.124 & 0.939\end{array}$

d. Russell 2000

\begin{tabular}{ccccccc|ccc|cc}
$1988-2004$ & Mean (\%) & -0.086 & 0.027 & 0.082 & 0.050 & 0.042 & value & 12.467 & 0.000 & 0.0032 & 0.0021 \\
(NO: & 744) & $\underline{\text { t-value }}$ & $-2.181^{* *}$ & 0.809 & $2.293^{* *}$ & 1.327 & 1.207 & prob. & 0.014 & 0.877 &
\end{tabular}

e. FTSE 100

\begin{tabular}{ccccccc|ccc|cc}
$1990-2004$ & Mean (\%) & -0.005 & 0.020 & -0.035 & 0.046 & 0.016 & value & 2.546 & 0.277 & 0.0006 & -0.0004 \\
(NO: 677$)$ & $\underline{\text { t-value }}$ & -0.121 & 0.547 & -0.984 & 1.089 & 0.398 & prob. & 0.636 & 0.567 &
\end{tabular}

f. Nikkei 225

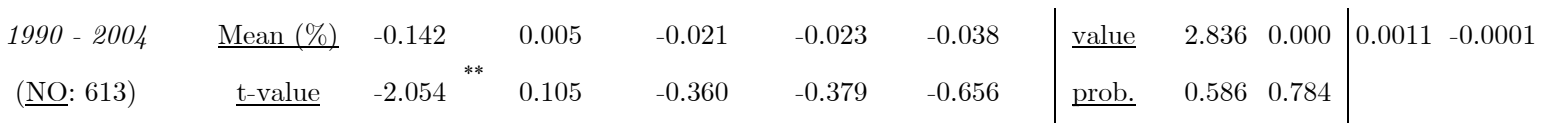

g. $V W D$

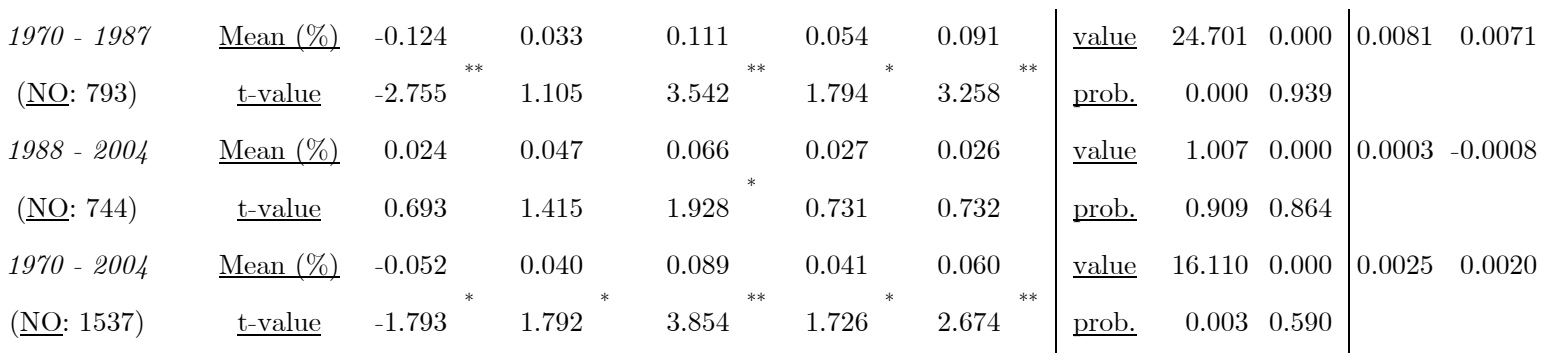




\begin{tabular}{|c|c|c|c|c|c|c|c|c|c|c|c|c|c|c|c|c|}
\hline $1970-1987$ & Mean (\%) & -0.152 & \multirow{2}{*}{$* *$} & 0.017 & & 0.101 & \multirow{2}{*}{$* *$} & 0.043 & & 0.075 & \multirow{2}{*}{$* *$} & value & 27.872 & 0.000 & \multirow[t]{2}{*}{0.0093} & \multirow[t]{2}{*}{0.0083} \\
\hline (ㅇ: 793$)$ & $\underline{\mathrm{t} \text {-value }}$ & -3.384 & & 0.566 & & 3.229 & & 1.433 & & 2.699 & & prob. & 0.000 & 0.421 & & \\
\hline $1988-2004$ & Mean (\%) & 0.012 & & 0.040 & & 0.055 & & 0.019 & & 0.019 & & $\underline{\text { value }}$ & 0.979 & 0.000 & \multirow[t]{2}{*}{0.0003} & \multirow[t]{2}{*}{-0.0008} \\
\hline ( $\underline{\mathrm{NO}}: 744)$ & $\underline{\mathrm{t} \text {-value }}$ & 0.336 & & 1.181 & & 1.618 & & 0.522 & & 0.538 & & prob. & 0.913 & 0.854 & & \\
\hline $1970-2004$ & Mean (\%) & -0.073 & \multirow{2}{*}{$3^{* *}$} & 0.028 & & 0.079 & \multirow[b]{2}{*}{$2^{* *}$} & 0.032 & & 0.048 & \multirow{2}{*}{ ** } & $\underline{\text { value }}$ & 18.587 & 0.000 & \multirow[t]{2}{*}{0.0029} & \multirow[t]{2}{*}{0.0024} \\
\hline ( $\underline{\mathrm{NO}}: 1573)$ & $\underline{\mathrm{t} \text {-value }}$ & -2.506 & & 1.251 & & 3.412 & & 1.332 & & 2.160 & & prob. & 0.001 & 0.578 & & \\
\hline \multicolumn{17}{|l|}{ i. $E W D$} \\
\hline $1970-1987$ & Mean (\%) & -0.144 & \multirow{2}{*}{$4^{* *}$} & -0.054 & \multirow{2}{*}{${ }^{* *}$} & 0.110 & \multirow[b]{2}{*}{$7^{* *}$} & 0.106 & & 0.219 & \multirow{2}{*}{$5^{* *}$} & $\underline{\text { value }}$ & 118.01 & 0.000 & \multirow[t]{2}{*}{0.0287} & \multirow[t]{2}{*}{0.0277} \\
\hline (ㅇ: $: 793)$ & $\underline{\mathrm{t} \text {-value }}$ & -3.930 & & -2.050 & & 4.097 & & 4.137 & $* *$ & 8.896 & & prob. & 0.000 & 0.304 & & \\
\hline $1988-2004$ & Mean (\%) & -0.040 & & 0.054 & \multirow{2}{*}{$* *$} & 0.126 & \multirow{2}{*}{$* *$} & 0.134 & & 0.204 & \multirow{2}{*}{$4^{* *}$} & value & 63.123 & 0.000 & \multirow[t]{2}{*}{0.0133} & \multirow[t]{2}{*}{0.0122} \\
\hline ( $\underline{\mathrm{NO}}: 744)$ & $\underline{\text { t-value }}$ & -1.386 & & 2.234 & & 4.753 & & 4.856 & ${ }^{* *}$ & 8.012 & & prob. & 0.000 & 0.734 & & \\
\hline $1970-2004$ & Mean (\%) & -0.094 & \multirow{2}{*}{${ }^{* *}$} & -0.002 & & 0.118 & \multirow{2}{*}{$4^{* *}$} & 0.120 & & 0.212 & \multirow{2}{*}{$3^{2}$} & $\underline{\text { value }}$ & 173.33 & 0.000 & \multirow[t]{2}{*}{0.0206} & \multirow[t]{2}{*}{0.0201} \\
\hline ( $\underline{\mathrm{NO}}: 1573)$ & $\underline{\mathrm{t} \text {-value }}$ & -3.936 & & -0.101 & & 6.214 & & 6.287 & & 12.023 & & prob. & 0.000 & 0.302 & & \\
\hline \multicolumn{17}{|l|}{$j . E W X$} \\
\hline $1970-1987$ & Mean (\%) & -0.164 & \multirow{2}{*}{$5^{4 *}$} & -0.064 & & 0.105 & & 0.101 & & 0.210 & & $\underline{\text { value }}$ & 123.22 & 0.000 & 0.0304 & 0.0294 \\
\hline (ㅇ: $: 793)$ & $\underline{\mathrm{t} \text {-value }}$ & -4.465 & & -2.425 & ${ }^{* *}$ & 3.890 & ** & 3.916 & 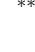 & 8.530 & & prob. & 0.000 & 0.878 & & \\
\hline $1988-2004$ & Mean $(\%)$ & -0.048 & & 0.049 & & 0.117 & & 0.129 & & 0.199 & & $\underline{\text { value }}$ & 64.306 & 0.000 & 0.0136 & 0.0125 \\
\hline ( $\underline{\mathrm{NO}}: 744)$ & $\underline{\mathrm{t} \text {-value }}$ & -1.677 & & 2.017 & & 4.424 & & 4.661 & & 7.800 & & prob. & 0.000 & 0.734 & & \\
\hline $1970-2004$ & Mean (\%) & -0.108 & & -0.010 & & 0.111 & & 0.114 & & 0.205 & & $\underline{\text { value }}$ & 180.08 & 0.000 & 0.0215 & 0.0210 \\
\hline ( $\underline{\mathrm{NO}}: 1573$ ) & $\underline{\mathrm{t} \text {-value }}$ & -4.529 & & -0.519 & & 5.840 & & 5.996 & & 11.610 & & prob. & 0.000 & 0.287 & & \\
\hline
\end{tabular}

\# The t-values of the table are corrected using Newey-West's (1987) heteroskedasticity and autocorrelation consistent covariance matrix. W1 is the Wald (chi-square) statistic for the null hypothesis Ho: $\alpha_{1}=\alpha_{2}=\alpha_{3}=\alpha_{4}=\alpha_{5}$. W2 is the Wald test for the null hypothesis Ho: $\alpha_{1} \leq \alpha_{2}$ and $\alpha_{1} \leq \alpha_{3}$ and $\alpha_{1} \leq \alpha_{4}$ and $\alpha_{1} \leq \alpha_{5}$ (Wolak, 1987). NO is the number of observations per weekday.

* Significant at the $10 \%$ level.

** Significant at the $5 \%$ level. 
Table 1-2. Linear Quantile Regression Estimates\#

(unit: \%)

\begin{tabular}{|c|c|c|c|c|c|c|c|c|c|}
\hline & & q & Mon. & Tue. & Wed. & Thu. & Fri. & $\mathbf{W}$ & $\mathrm{p}$ \\
\hline \multirow[t]{9}{*}{ a. $V W D$} & \multirow{3}{*}{$\begin{array}{l}1970- \\
1987\end{array}$} & $\underline{0.25}$ & $-0.625^{* *}(0.045)$ & $-0.478^{* *}(0.040)$ & $-0.394^{* *}(0.041)$ & $-0.366^{* *}(0.035)$ & $-0.379^{* *}(0.035)$ & 26.35 & 0.000 \\
\hline & & $\underline{0.5}$ & $-0.075^{* *}(0.034)$ & $(0.034)$ & $0.129^{* *}(0.030)$ & $0.042 \quad(0.027)$ & $0.055^{*} \quad(0.030)$ & 20.88 & 0.000 \\
\hline & & $\underline{0.75}$ & $0.431^{* *}(0.039)$ & $0.527 * *(0.036)$ & $0.539^{* *}(0.034)$ & $0.465^{* *}(0.035)$ & $0.529 * *(0.035)$ & 6.71 & 0.152 \\
\hline & \multirow{3}{*}{$\begin{array}{l}1988- \\
2004\end{array}$} & $\underline{0.25}$ & $-0.387^{* *}(0.042)$ & $-0.417^{* *}(0.041)$ & $-0.383^{* *}(0.042)$ & $-0.441^{* *}(0.045)$ & $-0.427^{* *}(0.045)$ & 1.36 & 0.850 \\
\hline & & $\underline{0.5}$ & $0.094^{* *}(0.031)$ & $0.051^{*} \quad(0.030)$ & $0.106^{* *}(0.029)$ & $0.036 \quad(0.031)$ & $0.088^{* *}(0.032)$ & 3.89 & 0.421 \\
\hline & & $\underline{0.75}$ & $0.535^{* *}(0.038)$ & $0.520^{* *}(0.041)$ & $0.511^{* *}(0.036)$ & $0.539 * *(0.043)$ & $0.517 * *(0.037)$ & 0.38 & 0.984 \\
\hline & \multirow{3}{*}{$\begin{array}{l}1970- \\
2004\end{array}$} & $\underline{0.25}$ & $-0.495^{* *}(0.032)$ & $-0.453^{* *}(0.030)$ & $-0.384^{* *}(0.029)$ & $-0.391^{* *}(0.027)$ & $-0.390^{* *}(0.027)$ & 10.72 & 0.030 \\
\hline & & $\underline{0.5}$ & $0.011 \quad(0.023)$ & $0.044^{* *}(0.022)$ & $0.116^{* *}(0.021)$ & $0.039 * \quad(0.020)$ & $0.075^{* *}(0.022)$ & 13.92 & 0.008 \\
\hline & & $\underline{0.75}$ & $0.490^{* *}(0.028)$ & $0.526^{* *}(0.027)$ & $0.534^{* *}(0.025)$ & $0.495^{* *}(0.027)$ & $0.527 * *(0.026)$ & 2.32 & 0.678 \\
\hline \multirow[t]{9}{*}{ b. $V W X$} & \multirow{3}{*}{$\begin{array}{l}1970- \\
1987\end{array}$} & $\underline{0.25}$ & $-0.651^{* *}(0.045)$ & $-0.502^{* *}(0.040)$ & $-0.403^{* *}(0.041)$ & $-0.383^{* *}(0.035)$ & $-0.387^{* *}(0.034)$ & 29.93 & 0.000 \\
\hline & & $\underline{0.5}$ & $-0.093^{* *}(0.034)$ & $0.020 \quad(0.034)$ & $0.119^{* *}(0.030)$ & $0.034 \quad(0.027)$ & $0.043 \quad(0.030)$ & 22.69 & 0.000 \\
\hline & & $\underline{0.75}$ & $0.394^{* *}(0.038)$ & $0.503^{* *}(0.035)$ & $0.533^{* *}(0.034)$ & $0.452^{* *}(0.035)$ & $0.513^{* *}(0.035)$ & 9.37 & 0.052 \\
\hline & \multirow{3}{*}{$\begin{array}{l}1988- \\
2004\end{array}$} & $\underline{0.25}$ & $-0.389^{* *}(0.040)$ & $-0.430 * *(0.041)$ & $-0.397^{* *}(0.043)$ & $-0.445^{* *}(0.045)$ & $-0.433^{* *}(0.044)$ & 1.33 & 0.857 \\
\hline & & $\underline{0.5}$ & $0.080^{* *}(0.031)$ & $0.043 \quad(0.030)$ & $0.091^{* *}(0.029)$ & $0.026 \quad(0.031)$ & $0.084^{* *}(0.032)$ & 3.51 & 0.477 \\
\hline & & $\underline{0.75}$ & $0.524^{* *}(0.038)$ & $0.513^{* *}(0.041)$ & $0.499^{* *}(0.036)$ & $0.530 * *(0.043)$ & $0.511^{* *}(0.037)$ & 0.39 & 0.983 \\
\hline & \multirow{3}{*}{$\begin{array}{l}1970- \\
2004\end{array}$} & $\underline{0.25}$ & $-0.518^{* *}(0.032)$ & $-0.465^{* *}(0.029)$ & $-0.397^{* *}(0.029)$ & $-0.404^{* *}(0.028)$ & $-0.398^{* *}(0.027)$ & 12.66 & 0.013 \\
\hline & & $\underline{0.5}$ & $-0.014 \quad(0.023)$ & $0.031 \quad(0.022)$ & $0.106^{* *}(0.021)$ & $0.030 \quad(0.020)$ & $0.065^{* *}(0.022)$ & 17.06 & 0.002 \\
\hline & & $\underline{0.75}$ & $0.468^{* *}(0.028)$ & $0.511^{* *}(0.027)$ & $0.526^{* *}(0.025)$ & $0.482^{* *}(0.027)$ & $0.513^{* *}(0.025)$ & 3.28 & 0.513 \\
\hline \multirow[t]{9}{*}{ c.EWD } & \multirow{3}{*}{$\begin{array}{l}1970- \\
1987\end{array}$} & $\underline{0.25}$ & $-0.483^{* *}(0.036)$ & $-0.380^{* *}(0.029)$ & $-0.219 * *(0.030)$ & $-0.174^{* *}(0.028)$ & $-0.082^{* *}(0.027)$ & 109.2 & 0.000 \\
\hline & & $\underline{0.5}$ & $-0.073^{* *}(0.025)$ & $-0.020 \quad(0.026)$ & $0.125^{* *}(0.023)$ & $0.158^{* *}(0.022)$ & $0.254^{* *}(0.022)$ & 124.5 & 0.000 \\
\hline & & $\underline{0.75}$ & $0.295^{* *}(0.030)$ & $0.351^{* *}(0.026)$ & $0.451^{* *}(0.025)$ & $0.459^{* *}(0.023)$ & $0.555^{* *}(0.024)$ & 59.97 & 0.000 \\
\hline & \multirow{3}{*}{$\begin{array}{l}1988- \\
2004\end{array}$} & $\underline{0.25}$ & $-0.345^{* *}(0.033)$ & $-0.225^{* *}(0.028)$ & $-0.148^{* *}(0.032)$ & $-0.157^{* *}(0.031)$ & $-0.070 * *(0.029)$ & 42.92 & 0.000 \\
\hline & & $\underline{0.5}$ & $0.026 \quad(0.025)$ & $0.088^{* *}(0.022)$ & $0.183^{* *}(0.022)$ & $0.181^{* *}(0.023)$ & $0.264^{* *}(0.021)$ & 65.24 & 0.000 \\
\hline & & $\underline{0.75}$ & $0.383^{* *}(0.027)$ & $0.390^{* *}(0.025)$ & $0.494^{* *}(0.025)$ & $0.490^{* *}(0.023)$ & $0.529^{* *}(0.022)$ & 29.12 & 0.000 \\
\hline & \multirow{3}{*}{$\begin{array}{l}1970- \\
2004\end{array}$} & $\underline{0.25}$ & $-0.413^{* *}(0.025)$ & $-0.309^{* *}(0.021)$ & $-0.194^{* *}(0.022)$ & $-0.166^{* *}(0.021)$ & $-0.080^{* *}(0.020)$ & 136.2 & 0.000 \\
\hline & & $\underline{0.5}$ & $-0.029 \quad(0.018)$ & $0.042^{* *}(0.017)$ & $0.156^{* *}(0.016)$ & $0.168^{* *}(0.016)$ & $0.258^{* *}(0.015)$ & 187.8 & 0.000 \\
\hline & & $\underline{0.75}$ & $0.333^{* *}(0.020)$ & $0.366^{* *}(0.017)$ & $0.480^{* *}(0.018)$ & $0.476^{* *}(0.016)$ & $0.542^{* *}(0.016)$ & 94.99 & 0.000 \\
\hline \multirow[t]{6}{*}{ d.EWX } & \multirow{3}{*}{$\begin{array}{l}1970- \\
1987\end{array}$} & $\underline{0.25}$ & $-0.503^{* *}(0.036)$ & $-0.387^{* *}(0.029)$ & $-0.222^{* *}(0.029)$ & $-0.182^{* *}(0.028)$ & $-0.092^{* *}(0.027)$ & 112.4 & 0.000 \\
\hline & & $\underline{0.5}$ & $-0.098^{* *}(0.025)$ & $-0.024 \quad(0.025)$ & $0.120^{* *}(0.023)$ & $0.155^{* *}(0.022)$ & $0.248^{* *}(0.022)$ & 136.2 & 0.000 \\
\hline & & $\underline{0.75}$ & $0.279^{* *}(0.030)$ & $0.343^{* *}(0.026)$ & $0.446^{* *}(0.025)$ & $0.453^{* *}(0.023)$ & $0.550^{* *}(0.024)$ & 63.92 & 0.000 \\
\hline & \multirow{3}{*}{$\begin{array}{l}1988- \\
2004\end{array}$} & $\underline{0.25}$ & $-0.349^{* *}(0.033)$ & $-0.235^{* *}(0.028)$ & $-0.159^{* *}(0.032)$ & $-0.161^{* *}(0.030)$ & $-0.074^{* *}(0.029)$ & 43.93 & 0.000 \\
\hline & & $\underline{0.5}$ & $0.014 \quad(0.025)$ & $0.085^{* *}(0.022)$ & $0.178^{* *}(0.022)$ & $0.176^{* *}(0.023)$ & $0.261^{* *}(0.021)$ & 68.53 & 0.000 \\
\hline & & 0.75 & $0.372^{* *}(0.027)$ & $0.386^{* *}(0.025)$ & $0.486^{* *}(0.025)$ & $0.486^{* *}(0.023)$ & $0.525^{* *}(0.022)$ & 30.13 & 0.000 \\
\hline
\end{tabular}




\begin{tabular}{lllllllll}
\hline $1970-$ & $\underline{0.25}$ & $-0.428^{* *}(0.025)$ & $-0.318^{* *}(0.021)$ & $-0.200^{* *}(0.022)$ & $-0.171^{* *}(0.021)$ & $-0.084^{* *}(0.020)$ & 145.2 & 0.000 \\
2004 & $\underline{0.5}$ & $-0.039^{* *}(0.018)$ & $0.034^{* *}(0.017)$ & $0.151^{* *}(0.016)$ & $0.163^{* *}(0.016)$ & $0.256^{* *}(0.015)$ & 198.9 & 0.000 \\
& $\underline{0.75}$ & $0.321^{* *}(0.020)$ & $0.357^{* *}(0.017)$ & $0.469^{* *}(0.018)$ & $0.470^{* *}(0.016)$ & $0.539^{* *}(0.016)$ & 100.8 & 0.000 \\
\hline
\end{tabular}

\# Standard errors are in parentheses. They are obtained through kernel density estimation. We select (sample size) $)^{\wedge}(-0.1)$ for the band width. W is the Wald (chi-square) statistic for the null hypothesis Ho: $\alpha_{1}=\alpha_{2}=\alpha_{3}=\alpha_{4}=\alpha_{5}$, and p is p-value of W. * Significant at the $10 \%$ level.

** Significant at the $5 \%$ level. 
Table 1-3. OLS Estimates" (Dependent variable: $\varepsilon^{2}$ )

$\begin{array}{llclllll}\text { Mon. Tue. Wed. Thu. } & \text { Fri. } & \text { W } & \text { Wc } & R^{2} & \bar{R}^{2}\end{array}$ a. $V W D$

\begin{tabular}{|c|c|c|c|c|c|c|c|c|c|c|c|}
\hline $1970-1987$ & Mean $(\%)$ & 1.339 & 0.702 & 0.830 & 0.701 & 0.644 & $\underline{\text { value }}$ & 6.264 & 16.802 & 0.0025 & 0.0015 \\
\hline (요 $: 793)$ & $\underline{\text { t-value }}$ & $3.218^{\text {** }}$ & $14.206^{* *}$ & $7.225^{* *}$ & $10.547^{* *}$ & $11.782^{\text {** }}$ & prob. & 0.180 & 0.002 & & \\
\hline $1988-2004$ & Mean (\%) & 1.063 & 0.876 & 0.830 & 0.939 & 1.009 & $\underline{\text { value }}$ & 5.757 & 97.080 & 0.0012 & 0.0002 \\
\hline ( $\underline{\mathrm{NO}}: 744)$ & $\underline{\text { t-value }}$ & $8.616^{* *}$ & $11.159^{* *}$ & $11.449^{* *}$ & $11.547^{* *}$ & $9.686^{* *}$ & prob. & 0.218 & 0.000 & & \\
\hline $1970-2004$ & Mean (\%) & 1.211 & 0.786 & 0.830 & 0.816 & 0.822 & $\underline{\text { value }}$ & 4.137 & 55.124 & 0.0016 & 0.0010 \\
\hline (으: 1537) & $\underline{\text { t-value }}$ & $5.338^{* *}$ & $16.665^{* *}$ & $11.864^{* *}$ & $15.160^{* *}$ & $13.739^{* *}$ & prob. & 0.388 & 0.000 & & \\
\hline
\end{tabular}

b. $V W X$

\begin{tabular}{|c|c|c|c|c|c|c|c|c|c|c|}
\hline $1970-1987$ & Mean (\%) & 1.341 & 0.702 & 0.828 & 0.700 & 0.642 & value & 6.407 & 16.813 & 0.0026 \\
\hline ( $\underline{\mathrm{NO}}: 793)$ & $\underline{\mathrm{t} \text {-value }}$ & $3.229^{* *}$ & $14.202^{* *}$ & $7.214^{* *}$ & $10.555^{* *}$ & $11.758^{* *}$ & prob. & 0.171 & 0.002 & \\
\hline $1988-2004$ & Mean $(\%)$ & 1.062 & 0.876 & 0.830 & 0.939 & 1.010 & value & 5.800 & 97.206 & 0.0012 \\
\hline ( $\underline{\mathrm{NO}}: 744)$ & $\underline{\mathrm{t} \text {-value }}$ & $8.616^{* *}$ & $11.152^{* *}$ & $11.438^{* *}$ & $11.547^{* *}$ & $9.705^{* *}$ & prob. & 0.215 & 0.000 & \\
\hline $1970-2004$ & Mean (\%) & 1.213 & 0.786 & 0.829 & 0.816 & 0.821 & value & 4.209 & 54.954 & 0.0016 \\
\hline (ㅇ: 1573 ) & $\underline{t \text {-value }}$ & $5.351^{* *}$ & $16.657^{* *}$ & $11.850^{* *}$ & $15.164^{* *}$ & $13.745^{\text {** }}$ & prob. & 0.379 & 0.000 & \\
\hline
\end{tabular}

c. $E W D$

\begin{tabular}{|c|c|c|c|c|c|c|c|c|c|c|c|c|}
\hline $1970-1987$ & Mean $(\%)$ & 0.855 & 0.485 & & 0.578 & 0.479 & 0.451 & $\underline{\text { value }}$ & 9.725 & 34.740 & 0.0029 & 0.0019 \\
\hline (으: 793$)$ & $\underline{\mathrm{t} \text {-value }}$ & $4.529^{* *}$ & 5.696 & ** & $5.722^{* *}$ & $7.545^{* *}$ & $7.733^{* *}$ & prob. & 0.045 & 0.000 & & \\
\hline $1988-2004$ & Mean $(\%)$ & 0.641 & 0.427 & & 0.477 & 0.500 & 0.492 & $\underline{\text { value }}$ & 8.330 & 58.679 & 0.0022 & 0.0012 \\
\hline ( $\underline{\mathrm{NO}}: 744)$ & $\underline{\mathrm{t} \text {-value }}$ & $8.342^{* *}$ & 10.281 & ** & $11.151^{* *}$ & $8.871^{* *}$ & $7.104^{* *}$ & prob. & 0.080 & 0.000 & & \\
\hline $1970-2004$ & Mean $(\%)$ & 0.754 & 0.460 & & 0.529 & 0.490 & 0.471 & $\underline{\text { value }}$ & 16.542 & 82.977 & 0.0024 & 0.0018 \\
\hline (ㅇ: 1573 ) & $\underline{\mathrm{t} \text {-value }}$ & $7.075^{\text {** }}$ & 9.333 & ** & $9.300^{* *}$ & $11.231^{* *}$ & $10.266^{* *}$ & prob. & 0.002 & 0.000 & & \\
\hline
\end{tabular}

d. $E W X$

\begin{tabular}{|c|c|c|c|c|c|c|c|c|c|c|c|}
\hline $1970-1987$ & Mean $(\%)$ & 0.855 & 0.485 & 0.578 & 0.479 & 0.450 & $\underline{\text { value }}$ & 9.724 & 34.700 & 0.0029 & 0.0019 \\
\hline ( $\underline{\mathrm{NO}}: 793)$ & $\underline{\mathrm{t} \text {-value }}$ & $4.535^{\text {** }}$ & $5.707^{* *}$ & $5.720^{* *}$ & $7.541^{* *}$ & $7.718^{* *}$ & prob. & 0.045 & 0.000 & & \\
\hline $1988-2004$ & $\underline{\text { Mean }(\%)}$ & 0.641 & 0.427 & 0.477 & 0.500 & 0.492 & value & 8.329 & 58.649 & 0.0022 & 0.0012 \\
\hline ( $\underline{\mathrm{NO}}: 744)$ & $\underline{\mathrm{t} \text {-value }}$ & $8.342^{* *}$ & $10.285^{* *}$ & $11.142^{* *}$ & $8.873^{* *}$ & $7.112^{* *}$ & prob. & 0.080 & 0.000 & & \\
\hline $1970-2004$ & Mean (\%) & 0.755 & 0.460 & 0.529 & 0.490 & 0.470 & value & 16.527 & 82.829 & 0.0024 & 0.0019 \\
\hline (ㅇ: 1573 ) & $\underline{\mathrm{t} \text {-value }}$ & $7.084^{\text {** }}$ & $9.347^{* *}$ & $9.300^{* *}$ & $11.230^{* *}$ & $10.264^{* *}$ & prob. & 0.002 & 0.000 & & \\
\hline
\end{tabular}

\footnotetext{
${ }^{\#}$ The t-values of the table are corrected using Newey-West's (1987) heteroskedasticity and autocorrelation consistent covariance matrix. W is the Wald (chi-square) statistic for the null hypothesis Ho: $\alpha_{1}=\alpha_{2}=\alpha_{3}=\alpha_{4}=\alpha_{5}$. Wc is the Wald statistic for the null hypothesis Ho: $\alpha_{1}=3 \alpha_{2}=3 \alpha_{3}=3 \alpha_{4}=3 \alpha_{5}$. NO is the number of observations per weekday. VWD is the value-weighted CRSP index including dividends. VWX is the value-weighted CRSP index excluding dividends. EWD is the value-weighted CRSP index including dividends. EWX is the value-weighted CRSP index excluding dividends.

* Significant at the $10 \%$ level.

** Significant at the 5\% level.
} 
Table 2. Median of P-Values*

(Subsampling, subsample range: $N^{0.3} \sim N^{0.7}$, number of p-values $=30$ )

\begin{tabular}{|c|c|c|c|c|c|c|c|c|c|c|}
\hline & Period & Order & $\mathbf{I}$ & II & III & IV & V & VI & VII & VIII \\
\hline \multirow[t]{9}{*}{ a. DJIA } & 1970 & $\underline{1 \mathrm{st}}$ & 0.4574 & 0.0026 & 0.0032 & 0.4541 & 0.0978 & 0.1289 & 0.2800 & 0.0032 \\
\hline & -1987 & $\underline{2 n d}$ & 0.8185 & 0.0048 & 0.0104 & 0.5630 & 0.0937 & 0.7262 & 0.8185 & 0.0104 \\
\hline & & $\underline{3 \mathrm{rd}}$ & 0.7211 & 0.0107 & 0.0107 & 0.5235 & 0.0483 & 0.5558 & 0.7211 & 0.0107 \\
\hline & 1988 & $\underline{1 \mathrm{st}}$ & 0.1556 & 0.8008 & 0.7105 & 0.0036 & 0.4273 & 0.1971 & 0.6570 & 0.1556 \\
\hline & -2004 & $\underline{2 n d}$ & 0.1478 & 0.5061 & 0.4435 & 0.1241 & 0.0000 & 0.1919 & 0.1885 & 0.1610 \\
\hline & & $\underline{3 \mathrm{rd}}$ & 0.0498 & 0.4283 & 0.4069 & 0.2224 & 0.0530 & 0.4284 & 0.1693 & 0.1078 \\
\hline & 1970 & $\underline{1 \mathrm{st}}$ & 0.2570 & 0.1947 & 0.3137 & 0.2848 & 0.1626 & 0.1279 & 0.0108 & 0.5008 \\
\hline & -2004 & $\underline{2 n d}$ & 0.8361 & 0.0976 & 0.0981 & 0.6003 & 0.7347 & 0.7001 & 0.8361 & 0.1773 \\
\hline & & $\underline{3 \mathrm{rd}}$ & 0.7578 & 0.0559 & 0.0559 & 0.5632 & 0.6333 & 0.5402 & 0.7578 & 0.0559 \\
\hline \multirow[t]{9}{*}{ b. $S E P 500$} & 1970 & $\underline{1 \mathrm{st}}$ & 0.4178 & 0.0329 & 0.0000 & 0.8650 & 0.8660 & 0.1587 & 0.2608 & 0.0000 \\
\hline & -1987 & $\underline{\text { 2nd }}$ & 0.7125 & 0.0027 & 0.0081 & 0.5035 & 0.1128 & 0.6519 & 0.7125 & 0.0081 \\
\hline & & $\underline{3 \mathrm{rd}}$ & 0.6178 & 0.0107 & 0.0107 & 0.4848 & 0.1703 & 0.4986 & 0.6178 & 0.0107 \\
\hline & 1988 & $\underline{1 \mathrm{st}}$ & 0.2944 & 0.6223 & 0.8446 & 0.0733 & 0.4904 & 0.4420 & 0.8023 & 0.3126 \\
\hline & -2004 & $\underline{2 n d}$ & 0.4102 & 0.5202 & 0.5641 & 0.2723 & 0.4580 & 0.2598 & 0.2921 & 0.6383 \\
\hline & & $\underline{3 \mathrm{rd}}$ & 0.1614 & 0.4356 & 0.4345 & 0.6878 & 0.7563 & 0.4656 & 0.1470 & 0.3990 \\
\hline & 1970 & $\underline{1 \mathrm{st}}$ & 0.4735 & 0.1437 & 0.0873 & 0.5118 & 0.6428 & 0.0329 & 0.1737 & 0.1696 \\
\hline & -2004 & $\underline{2 n d}$ & 0.7272 & 0.0383 & 0.0413 & 0.5432 & 0.8844 & 0.6342 & 0.7272 & 0.0415 \\
\hline & & $\underline{3 \mathrm{rd}}$ & 0.6782 & 0.0559 & 0.0559 & 0.5310 & 0.8291 & 0.4881 & 0.6782 & 0.0559 \\
\hline \multirow[t]{3}{*}{ c. $N A S D A Q$} & 1988 & $\underline{1 \mathrm{st}}$ & 0.2647 & 0.0884 & 0.0587 & 0.8937 & 0.3181 & 0.0027 & 0.1066 & 0.0587 \\
\hline & -2004 & $\underline{2 n d}$ & 0.8535 & 0.0034 & 0.0788 & 0.3709 & 0.0888 & 0.7439 & 0.8488 & 0.0788 \\
\hline & & $\underline{3 \mathrm{rd}}$ & 0.7275 & 0.0000 & 0.0370 & 0.3695 & 0.0262 & 0.4768 & 0.7051 & 0.0370 \\
\hline \multirow[t]{3}{*}{ d. Russell 2000} & 1988 & $\underline{1 \mathrm{st}}$ & 0.9596 & 0.0852 & 0.0545 & 0.3984 & 0.4884 & 0.8920 & 0.9588 & 0.0545 \\
\hline & -2004 & $\underline{2 n d}$ & 0.8560 & 0.0000 & 0.0201 & 0.4832 & 0.2934 & 0.8102 & 0.8560 & 0.0201 \\
\hline & & $\underline{3 \mathrm{rd}}$ & 0.6889 & 0.0000 & 0.0056 & 0.4750 & 0.0707 & 0.5556 & 0.6797 & 0.0056 \\
\hline \multirow[t]{3}{*}{ e. FTSE 100} & 1990 & $\underline{1 \mathrm{st}}$ & 0.5413 & 0.0159 & 0.3944 & 0.2527 & 0.2494 & 0.0068 & 0.1747 & 0.7713 \\
\hline & -2004 & $\underline{2 n d}$ & 0.5340 & 0.0293 & 0.3516 & 0.6388 & 0.0941 & 0.0198 & 0.3086 & 0.6133 \\
\hline & & $\underline{3 \mathrm{rd}}$ & 0.8225 & 0.0609 & 0.1430 & 0.6244 & 0.0270 & 0.6714 & 0.8225 & 0.2797 \\
\hline \multirow[t]{3}{*}{ f. Nikkei 225} & 1990 & $\underline{1 \mathrm{st}}$ & 0.2943 & 0.0000 & 0.1613 & 0.0964 & 0.0025 & 0.0000 & 0.0331 & 0.2182 \\
\hline & -2004 & $\underline{\text { 2nd }}$ & 0.7599 & 0.0101 & 0.0986 & 0.6397 & 0.8776 & 0.6984 & 0.7599 & 0.1046 \\
\hline & & $\underline{3 \mathrm{rd}}$ & 0.6935 & 0.0000 & 0.0389 & 0.6052 & 0.7837 & 0.5519 & 0.6935 & 0.0389 \\
\hline$g . V W D$ & 1970 & $\underline{1 \mathrm{st}}$ & 0.7947 & 0.0508 & 0.0000 & 0.9554 & 0.3001 & 0.7481 & 0.7940 & 0.0000 \\
\hline
\end{tabular}




\begin{tabular}{|c|c|c|c|c|c|c|c|c|c|}
\hline \multirow[t]{2}{*}{-1987} & $\underline{\text { nd }}$ & 0.6763 & 0.0000 & 0.0000 & 0.5007 & 0.0285 & 0.6274 & 0.6763 & 0.0000 \\
\hline & $\underline{3 \mathrm{rd}}$ & 0.5929 & 0.0096 & 0.0094 & 0.4761 & 0.0100 & 0.4960 & 0.5929 & 0.0094 \\
\hline 1988 & $\underline{1 \mathrm{st}}$ & 0.5186 & 0.3525 & 0.7921 & 0.4001 & 0.4279 & 0.6181 & 0.6449 & 0.7459 \\
\hline \multirow[t]{2}{*}{-2004} & $\underline{\text { 2nd }}$ & 0.8116 & 0.4148 & 0.4913 & 0.4580 & 0.8286 & 0.4917 & 0.7280 & 0.6410 \\
\hline & $\underline{3 \mathrm{rd}}$ & 0.8633 & 0.3119 & 0.1806 & 0.4488 & 0.7678 & 0.5569 & 0.8621 & 0.2722 \\
\hline 1970 & $\underline{1 \mathrm{st}}$ & 0.7990 & 0.0981 & 0.0151 & 0.5195 & 0.2088 & 0.5803 & 0.7594 & 0.0151 \\
\hline \multirow[t]{2}{*}{-2004} & $\underline{2 n d}$ & 0.7365 & 0.0004 & 0.0010 & 0.5559 & 0.7799 & 0.6370 & 0.7365 & 0.0010 \\
\hline & $\underline{3 \mathrm{rd}}$ & 0.6845 & 0.0197 & 0.0303 & 0.5405 & 0.7626 & 0.4968 & 0.6845 & 0.0303 \\
\hline 1970 & $\underline{1 \mathrm{st}}$ & 0.7712 & 0.0273 & 0.0000 & 0.9524 & 0.3462 & 0.7322 & 0.7675 & 0.0000 \\
\hline \multirow[t]{2}{*}{-1987} & $\underline{2 \mathrm{nd}}$ & 0.6424 & 0.0000 & 0.0000 & 0.4540 & 0.0102 & 0.6108 & 0.6424 & 0.0000 \\
\hline & $\underline{3 \mathrm{rd}}$ & 0.5547 & 0.0094 & 0.0093 & 0.4370 & 0.0106 & 0.4649 & 0.5547 & 0.0093 \\
\hline 1988 & $\underline{1 \mathrm{st}}$ & 0.4860 & 0.3756 & 0.7068 & 0.4530 & 0.2918 & 0.6209 & 0.4760 & 0.7212 \\
\hline \multirow[t]{2}{*}{-2004} & $\underline{2 n d}$ & 0.8980 & 0.3975 & 0.5007 & 0.4522 & 0.7825 & 0.7366 & 0.8943 & 0.6316 \\
\hline & $\underline{3 \mathrm{rd}}$ & 0.8627 & 0.1729 & 0.1668 & 0.4488 & 0.7592 & 0.5547 & 0.8604 & 0.2493 \\
\hline 1970 & $\underline{1 \mathrm{st}}$ & 0.8042 & 0.0920 & 0.0069 & 0.4558 & 0.3327 & 0.6143 & 0.7711 & 0.0069 \\
\hline \multirow[t]{2}{*}{-2004} & $\underline{\text { 2nd }}$ & 0.7237 & 0.0000 & 0.0000 & 0.5406 & 0.7834 & 0.6312 & 0.7237 & 0.0000 \\
\hline & $\underline{3 \mathrm{rd}}$ & 0.6609 & 0.0139 & 0.0222 & 0.5210 & 0.7554 & 0.4851 & 0.6609 & 0.0222 \\
\hline 1970 & 1st & 0.4567 & 0.1003 & 0.0000 & 0.4859 & 0.9846 & 0.3331 & 0.4567 & 0.0000 \\
\hline \multirow[t]{2}{*}{-1987} & $\underline{\text { 2nd }}$ & 0.7109 & 0.0000 & 0.0000 & 0.5675 & 0.8780 & 0.7056 & 0.7109 & 0.0000 \\
\hline & $\underline{3 \mathrm{rd}}$ & 0.6520 & 0.0000 & 0.0000 & 0.5675 & 0.7642 & 0.6371 & 0.6520 & 0.0000 \\
\hline 1988 & $\underline{1 \mathrm{st}}$ & 0.6195 & 0.0158 & 0.0000 & 0.4298 & 0.5004 & 0.3795 & 0.6186 & 0.0000 \\
\hline \multirow[t]{2}{*}{-2004} & $\underline{2 n d}$ & 0.6024 & 0.0000 & 0.0000 & 0.2547 & 0.1165 & 0.5334 & 0.6024 & 0.0000 \\
\hline & $\underline{3 \mathrm{rd}}$ & 0.4431 & 0.0000 & 0.0000 & 0.2044 & 0.0041 & 0.3755 & 0.4431 & 0.0000 \\
\hline 1970 & $1 \mathrm{st}$ & 0.3693 & 0.0027 & 0.0000 & 0.5697 & 0.9993 & 0.2181 & 0.3626 & 0.0000 \\
\hline \multirow[t]{2}{*}{-2004} & $\underline{\text { nd }}$ & 0.5969 & 0.0000 & 0.0000 & 0.4812 & 0.4717 & 0.5831 & 0.5969 & 0.0000 \\
\hline & $\underline{3 \mathrm{rd}}$ & 0.5328 & 0.0000 & 0.0000 & 0.4812 & 0.1447 & 0.4840 & 0.5328 & 0.0000 \\
\hline 1970 & $\underline{1 \mathrm{st}}$ & 0.3885 & 0.0701 & 0.0000 & 0.4773 & 0.9805 & 0.2608 & 0.3791 & 0.0000 \\
\hline \multirow[t]{2}{*}{-1987} & $\underline{2 n d}$ & 0.6977 & 0.0000 & 0.0000 & 0.5675 & 0.7714 & 0.6909 & 0.6977 & 0.0000 \\
\hline & $\underline{3 \mathrm{rd}}$ & 0.6493 & 0.0000 & 0.0000 & 0.5675 & 0.7532 & 0.6378 & 0.6493 & 0.0000 \\
\hline 1988 & $\underline{1 \mathrm{st}}$ & 0.6042 & 0.0237 & 0.0000 & 0.4234 & 0.4925 & 0.3701 & 0.6042 & 0.0000 \\
\hline \multirow[t]{2}{*}{-2004} & $\underline{\text { nd }}$ & 0.6031 & 0.0000 & 0.0000 & 0.2547 & 0.1039 & 0.5421 & 0.6031 & 0.0000 \\
\hline & $\underline{3 \mathrm{rd}}$ & 0.4452 & 0.0000 & 0.0000 & 0.2044 & 0.0041 & 0.3786 & 0.4452 & 0.0000 \\
\hline 1970 & $\underline{1 \mathrm{st}}$ & 0.3192 & 0.0031 & 0.0000 & 0.5636 & 0.9993 & 0.1566 & 0.3116 & 0.0000 \\
\hline \multirow[t]{2}{*}{-2004} & $\underline{2 n d}$ & 0.5931 & 0.0000 & 0.0000 & 0.4812 & 0.4631 & 0.5776 & 0.5931 & 0.0000 \\
\hline & $\underline{3 \mathrm{rd}}$ & 0.5314 & 0.0000 & 0.0000 & 0.4812 & 0.1468 & 0.4845 & 0.5314 & 0.0000 \\
\hline
\end{tabular}
*Null hypotheses are as follows. I : All other weekdays s-th order SD Monday, II : Monday s-th order SDs at least one weekday, III :
Monday s-th order SDs all other weekdays, IV : At least one weekday s-th order SDs Monday, V : At least one weekday s-th order 
SDs all others, VI : At least one weekday is s-th order SDed by all others, VII : Either rest of weekdays or Monday s-th order SDs the other, VIII : The distributions are all identical. 
Figure 1. (EWX, 1970 - 2004 )
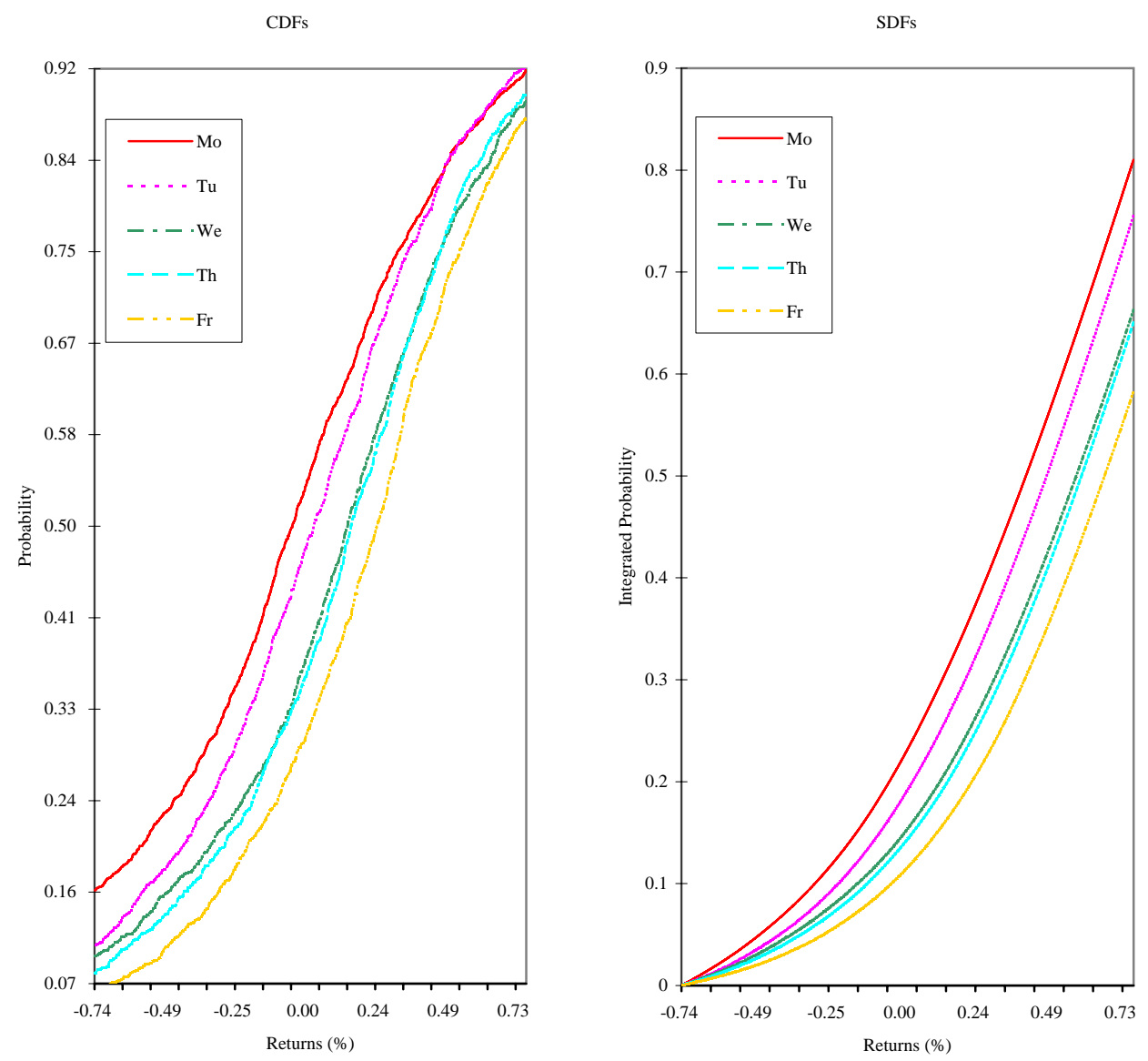